\title{
Title: Rat perichondrium transplanted to articular cartilage defects forms articular-like, hyaline cartilage
}

\author{
Running title: Perichondrium transplants form hyaline cartilage \\ Zelong Dou, M.Sc. ${ }^{1 *}$, Daniel Muder, M.D ${ }^{2 *}$, Marta Baroncelli, PhD. ${ }^{1}$, Ameya Bendre, PhD. ${ }^{1}$, \\ 11 Alexandra Gkourogianni, M.D, PhD. ${ }^{1}$, Lars Ottosson, PhD. ${ }^{1}$, Torbjörn Vedung, M.D., Ph.D. ${ }^{2,3}$, \\ Ola Nilsson, M.D., $\mathrm{PhD}^{1,4}$
}

*ZD and DM contributed equally to the manuscript.

1. Division of Pediatric Endocrinology and Center for Molecular Medicine, L8:01, Department of Women's and Children's Health, Karolinska Institutet and University Hospital, Stockholm, Sweden

2. Department of Surgical Sciences, Uppsala University, Uppsala, Sweden

3. Elisabeth Hospital, Aleris Healthcare, Uppsala, Sweden

4. School of Medical Sciences, Örebro University and University Hospital, Örebro, Sweden.

Corresponding author's e-mail and ground mail addresses, telephone and fax numbers:

Ola Nilsson, M.D., PhD., Professor, 
27 Grants or fellowships supporting the writing of the paper:

28 The work of D.M. and T.V. was supported by grants from the Uppsala County and D.M. was also supported by Dalarna County Council.

30 This work was supported by grants from the Swedish Research Council (project K2015-54X22 736-01-4 \& 2015-02227), the Swedish Governmental Agency for Innovation Systems (Vinnova) (2014-01438), Marianne and Marcus Wallenberg Foundation, the Stockholm

Kronprinsessan Lovisas förening för barnasjukvård, Sällskapet Barnavård, Stiftelsen

Frimurare Barnhuset i Stockholm, Promobilia, Nyckelfonden, and Karolinska Institutet, Stockholm, Sweden, and Örebro University, Örebro, Sweden.

Disclosure summary: None of the authors have any potential conflict of interests or anything to declare that is directly related to this work. ON has received consulting fees from Kyowa Kirin Inc and speakers' honoraria from Merck and Pfizer, and research funds to the department of ON from Kyowa Kirin and Novo Nordisk Foundation.

\section{Data availability}




\section{Abstract}

49

Reconstruction of articular surfaces destroyed by infection or trauma is hampered by the lack of suitable graft tissues. Perichondrium autotransplants have been used for this purpose. However, the role of the transplanted perichondrium in the healing of resurfaced joints have not been investigated. Perichondrial and periosteal tissues were harvested from rats hemizygous for a ubiquitously expressed enhanced green fluorescent protein (EGFP) transgene and transplanted into full-thickness articular cartilage defects at the trochlear groove of distal femur in wild-type littermates. As an additional control, cartilage defects were left without a transplant (no transplant control). Distal femurs were collected 3, 14, 56, 112 days after surgery. Transplanted cells and their progenies were readily detected in the defects of perichondrium and periosteum transplanted animals but not in defects left without a transplant. Perichondrium transplants expressed SOX9 and with time differentiated into a hyaline cartilage that expanded and filled out the defects with Col2a1positive chondrocytes and a matrix rich in proteoglycans. Interestingly, at later timepoints the cartilaginous perichondrium transplants were actively remodeled into bone at the transplant-bone interface and at post-surgery day 112 EGFP-positive perichondrium cells at the articular surface were positive for Prg4. In addition, both perichondrium and periosteum transplants contributed cells to the subchondral bone and bone marrow, suggesting differentiation into osteoblast/osteocytes as well as bone marrow cells. In summary, we found that perichondrium transplanted to articular cartilage defects develops into an articular-like, hyaline cartilage that integrates with the subchondral bone, and is maintained for an extended time. The findings indicate that perichondrium is a suitable tissue for repair and engineering of articular cartilage.

Key words: Perichondrium, Transplantation, Articular cartilage, Injury, Chondrocyte differentiation 


\section{Introduction}

During development, bone formation is initiated by the condensation of immature mesenchymal cells that eventually lead to bone formation either by the intramembranous or endochondral route. In intramembranous bone formation a differentiation program controlled by transcription factors Runx2 and Osx, Wnt signaling and other factors leads to direct differentiation of preosteoblast and subsequently osteoblasts and osteocytes, which lay down a matrix rich in collagen type I (Col1) that is mineralized. In endochondral bone formation, mesenchymal cells undergo a program controlled by the chondrogenic transcription factor SOX9 and differentiate into chondrocytes that proliferate and produce a matrix rich in collagen type $\mathrm{II}(\mathrm{Col} 2)$ and proteoglycans forming the initial cartilaginous template in which chondrocytes will undergo hypertrophic differentiation switching from Col2 to collagen type $X($ ColX) expression, mineralize their matrix, and produce factors, e.g. vascular endothelial growth factor (VEGF) that attract invading vessel and bone cells that remodel the template into bone $e^{(1,2)}$. The cartilage templates are surrounded by perichondrium whereas bone tissue is surrounded by periosteum. Perichondrium and periosteum are similar in that they both consists of an outer fibrous layer and an inner cambium layer containing mesenchymal stem cells with both chondrogenic and osteogenic properties ${ }^{(3,4)}$. However, they have different functions during skeletal development, maintenance and repair ${ }^{(5-7)}$.

Joint formation occurs concomitantly with skeletal development and is first visible with the formation of interzones constituted of elongated, densely packed cells characterized by expression of GDF5, Gli3, Wnt4 and Wnt9a ${ }^{(8-10)}$, and low expression of Matn1 and Col2 ${ }^{(11)}$ and will eventually give rise to much of the synovial joint structures including the articular cartilage ${ }^{(8,12)}$. As the future joint cavitates, interzone cells closest to the cavity will start producing lubricin (Prg4) ${ }^{(12,13)}$ and these Prg4 positive cells will serve as progenitors for the underlying layers of the articular cartilage during postnatal life ${ }^{(14,15)}$. The synovial membrane produces synovial fluid, which is a blood-ultrafiltrate rich in hyaluronic acid, lubricin, and proteases, that fills up the joint cavity, and act together with lubricin expression at the joint surfaces to minimize friction. Low friction together with normal myogenesis and movement is crucial to the development of the mature joint ${ }^{(16)}$. 
108 Articular cartilage injury due to trauma, infection or degenerative diseases are common 109 causes of suffering and disability. These injuries can occur in all joints and appear throughout 110 all ages with massive socioeconomic consequences. Moreover, these injuries are difficult to 111 treat. One key issue is the poor regenerative capacity of articular cartilage ${ }^{(17,18)}$. Although 112 healing may occur under certain biological conditions, it is often absent or incomplete ${ }^{(18)}$. 113 The reasons for this inability to regenerate is not clear, but likely due to the structural and 114 physiological nature of this avascular and highly specialized tissue containing a limited 115 number of chondrocytes with slow turnover ${ }^{(19,20)}$. Consequently, a variety of surgical 116 techniques have been introduced in attempts to repair or regenerate articular cartilage, 117 including Pridie drilling and microfracturing methods ${ }^{(19,21)}$, autologous osteochondral 118 transplantation (mosaicplasty) ${ }^{(22-24)}$, osteochondral allografting ${ }^{(19)}$, autologous chondrocyte 119 implantation ${ }^{(25)}$, periosteal transplantation ${ }^{(26)}$, and perichondrial transplantation ${ }^{(27)}$.

121 The idea of using perichondrial transplantation to reconstruct articular cartilage surfaces originally stems from early observations that perichondrium has a high potential to produce cartilaginous tissue, e.g. in "cauliflower ear", the typical malformation that wrestlers develop after bumping and twisting their ears towards the opponent's head. The trauma causes a hemorrhage that lifts the perichondrium from the underlying cartilage and new cartilage is formed in the blood filled space ${ }^{(28)}$. This and subsequent observations that not only blood, 127 but also the synovial joint microenvironment was able to induce a chondrogenic program in the perichondrium led to the use of free perichondrium transplants to repair and resurface injured joints ${ }^{(27,29-31)}$. The method has been used in a variety of patients and joints, often with variable results ${ }^{(32-35)}$. Due to the need for a second surgical site at the ribcage, together with variability in the reported outcomes as well as improved orthopedic implants, the use of perichondrium transplantation declined. However, the technique is still in use and followup of patients treated with perichondrium transplants has indicated that the technique can produce functional articular surfaces that last over extended periods ${ }^{(36)}$, thus suggesting that perichondrium has the capacity to form an articular cartilage-like surface. However, the contribution of the transplanted perichondrium to the new joint surface and the quality of the resulting articular surfaces have been discussed ${ }^{(21)}$ but not formally investigated. In order

138 to address these questions, we used an inbred strain of rats with ubiquitous expression of 
140 harvested and transplanted into engineered articular cartilage injuries in EGFP-negative

141 littermates, thus allowing for cell-tracing of transplanted cells and their progenies and

142 evaluation of their contribution to and the quality of the resulting articular surfaces during 143 different phases of healing.

\section{Materials and methods}

\section{Animals}

147 All animal procedures were approved by the regional animal ethics committee in Stockholm 148 (Permit no. N248/15, N118/16, and 15635-2017). In order to trace transplanted cells, inbred 149 Lewis rats overexpressing EGFP under the ubiquitous CAG promote (Lew- $\mathrm{Tg}$ (CAGEGFP)YsRrrc; Rat Research and Resource Center, Columbia, MO, USA) were bred to wild-type resulting in a 1:1 ratio of transgenic hemizygous to wild-type animals. EGFP positive animals were used as donors and wild-type littermates as recipients ( $n=3$ for each group and timepoint, except for the no transplant group at day 14 post-surgery $(n=2))$. Animals were housed under standard conditions with a 12-hour light/dark cycle and received standard rat chow and fresh water ad libitum.

\section{Full thickness articular cartilage injury repair using perichondrial or periosteal transplants}

158 Six-week-old EGFP transgenic rats were euthanized by $\mathrm{CO}_{2}$ inhalation and with microsurgical technique perichondrial grafts were harvested from the cartilaginous part of the sternal ribs, and periosteal grafts were harvested from the anterior medial part of the tibia. To dissect the perichondrium grafts, the ventral part of the rib cage was cut loose with scissors. Under 4.5x loupe magnification two or three of the lower sternal ribs were detached from the sternum and separated from intercostal muscles with scalpel and forceps. The rib was put in a petri dish and kept moist with a few drops of saline. By use of a dissecting microscope (Carl Zeiss Stemi DV4 Series, Carl Zeiss, Oberkochen, Germany) with 10-40x magnification the cartilaginous part was distinguished from the osseus part of the rib. Under the microscope, a longitudinal cut was made through the perichondrium only, followed by careful dissection with micro scalpel and forceps peeling off the graft from the underlying cartilage. The perichondrial transplants were inspected and any residual cartilage was carefully removed 
171 peeled off the underlying medial part of the tibia in a similar fashion using the microscope.

172 The most intact parts of the grafts were cut into suitable sizes and kept moist in saline.

174 EGFP-negative littermates were sedated by inhalation of isoflurane/oxygen in a cage and 175 then maintained on mask isoflurane/oxygen. Heating blanket was used to maintain the body 176 temperature of the recipient animals during the surgery. Knees were shaved and scrubbed 177 with 70\% isopropryl alcohol, petrolatum eye ointment was administered to each eye, and normal saline $(5-10 \mathrm{ml})$ subcutaneously. The animals were induced with isoflurane and kept under general anesthesia using mask isoflurane. Knee joints were opened by a longitudinal incision lateral to the patella, which in turn was dislocated in medial direction, exposing the femoral condyles. At the intercondylar groove of the knee joint, 2 partly overlapping holes were punched out by using a 16-gauge Jamshidi bone marrow biopsy needle (BD Biosciences., NJ, USA). The edges of the holes were trimmed with a surgical scalpel and the bottom of the defect was curetted to expose the bleeding subchondral bone, creating an approximately 2x5 mm large full thickness articular cartilage injury. Trimmed EGFP-positive perichondrial or periosteal grafts were fitted to cover the defect and placed with the cambium layer facing towards the joint space. Attachment was made under the microscope with osteosutures at each corner of the transplant by using 8-0 none-absorbable monofilament. Two sutures were put in place and tied. The graft, still partially loose, was carefully lifted and a small amount of fibrin glue (TISSEEL, Baxter Healthcare Corporation, Westlake, CA, USA) was placed under the graft. Slight pressure was evenly applied to the graft for 60 seconds before completing the attachment by placing the two remaining sutures. Excess glue was carefully removed. The joint capsule and skin were closed in layers using 7.0 braded, resorbable sutures (Ethicon, Somerville, NJ, USA). OPSITE Spray (Smith \& Nephew, London, United Kingdom) was used to prevent potential inflammation caused by maceration. Bupivacaine $(2.5 \mathrm{mg} / \mathrm{ml})$ was injected around the surgical scar for local anesthesia. After the completion of surgery, meloxicam $(1 \mathrm{mg} / \mathrm{kg})$ or buprenorphine $(20-30$ $\mathrm{mcg} / \mathrm{kg}$ ) was administered every 12 hours during the first 48 hours. At post-surgery day 3, 14, 56 and 112, animals received an injection of 5-bromo-2'-deoxyuridine (BrdU; 50mg/kg) and were killed $4 \mathrm{hrs}$ later by carbon dioxide inhalation. Distal femoral epiphyses were rapidly excised, fixed (10\% formalin) overnight, decalcified (15\% EDTA, 0.5\% PFA) for 4 to 6 weeks, and photographed (Leica M320 dental microscope, Leica, Wetzlar, Germany) before 
203 being divided into two halves by a frontal cut in the center of the injury site and embedded 204 in paraffin or optimal cutting tissue compound (OCT; Histolab, Västra Frölunda, Sweden) 205 cyomount. Paraffin sections $(6 \mu \mathrm{m})$ were placed onto TruBOND 380 slides (Electron 206 Microscopy Sciences, Hatfield, PA, USA) and used for immunohistochemistry, in situ 207 hybridization and histological stainings. Frozen sections $(10 \mu \mathrm{m})$ were placed onto 208 SUPERFROST PLUS slides (Thermo Fisher Scientific, Waltham, MA, USA) and used for 209 immunofluorescence.

210

\section{Histological stainings}

212 Masson's trichrome Staining was applied according to the manufacturer's instructions of the 213 Trichrome Stain (Masson) Kit (HT15-1KT, Sigma-Aldrich, Heatherhouse, United Kingdom). For 214 Safranin O/Fast green staining, briefly, paraffin embedded tissue sections were baked at $65^{\circ} \mathrm{C}$ for $45 \mathrm{~min}$, deparaffinized in xylene, rehydrated through an ethanol series $(100 \%$, $100 \%, 95 \%$, and $70 \%)$, and rinsed in DEPC-treated water, followed by staining with Weigerts Hematoxylin for $5 \mathrm{~min}$, washed in distillated water, 2s of Acid Alcohol incubation, wash in distillated water, $0.02 \%$ Fast Green incubation for $5 \mathrm{~min}, 1 \%$ acetic acid incubation for $15 \mathrm{~s}$, then by $30 \mathrm{~min}$ of Safranin $\mathrm{O}$ incubation, rinse in $95 \%$ ethanol for $5 \mathrm{~min}$, dehydrated in an $95 \%$ $100 \%$ ethanol, cleared in xylene, and mounted with permount (Fisher Scientific, Fair Lawn, NJ, USA). Staining was visualized by scanning the slides under bright field microscopy with a Pannoramic MIDI II 2.0.5 digital scanner (3DHISTECH Ltd, Budapest, Hungary).

223

\section{Tracing of transplanted cells using GFP Immunohistochemistry}

225 In order to detect EGFP-positive cells, paraffin embedded tissue sections were baked at $65^{\circ} \mathrm{C}$ 226 for 1 hour, deparaffinized in xylene, rehydrated through an ethanol series (100\%, 100\%, 227 95\%, and 70\%), and rinsed in PBS. Antigen retrieval was performed using proteinase $\mathrm{K}$ (10 $228 \mu \mathrm{g} / \mathrm{ml}$ in PBS) at room temperature for $15 \mathrm{~min}$. Endogenous peroxidase activity was blocked 229 by incubation in $3 \% \mathrm{H}_{2} \mathrm{O}_{2}$ at room temperature for $15 \mathrm{~min}$ and non-specific binding was 230 blocked by a $1 \mathrm{~h}$ incubation in tris-buffered saline with tween $20(0.1 \mathrm{M}$ Tris, $0.15 \mathrm{M} \mathrm{NaCl}$, $2310.3 \% \mathrm{v} / \mathrm{v}$ Tween-20, pH7.5; TBST) containing 1\% BSA and 10\% goat serum before incubation 232 with the GFP primary antibody (anti-GFP antibody, ab290, Abcam, Cambridge, MA) overnight at $4^{\circ} \mathrm{C}$. Staining was performed using a VECTASTAIN ABC Kit (Vector Laboratories,

234 Burlingame, CA, USA) followed by a DAB Substrate Kit (Vector Laboratories) according to the 
235 manufacturer's instructions. All wash steps were carried out using $0.1 \%$ TBST. Tissue sections were counterstained with methyl green (Vector Laboratories), dehydrated in an ethanol series (95\%, 100\%, and $100 \%)$, cleared in xylene, and mounted in permount.

\section{Immunofluorescence}

240 In order to detect EGFP-positive cells of the donor allografts, OCT embedded tissue sections 241 were thawed and dried at $37^{\circ} \mathrm{C}$ for $30 \mathrm{~min}$, and rinsed in PBS 3 times to remove OCT. Antigen retrieval was performed in proteinase $\mathrm{K}(10 \mu \mathrm{g} / \mathrm{ml}$ in PBS) at room temperature for $3 \mathrm{~min}$, followed by incubation in TBST containing 1\% BSA and 10\% donkey serum for $1 \mathrm{~h}$ before incubation with primary antibody against GFP (\#ab290, Abcam) or SOX9 (anti-SOX9 antibody NBP1-85551, Novus Biologicals, Littleton, CO, USA) overnight at $+4^{\circ} \mathrm{C}$. The conjugated secondary antibody (Alexa Fluor 488, A-21206, Thermo Fisher Scientific) was incubated according to the manufacturer's instructions. All wash steps were performed using $0.1 \%$ TBST. Cell nuclei were stained with DAPI (D1306, Thermo Fisher Scientific), and slides mounted in ProLong ${ }^{\mathrm{TM}}$ Gold Antifade Mountant (P36930, Thermo Fisher Scientific). Confocal (ZEISS LSM 700) images were obtained under channels of GFP and DAPI for a z stack scanning of the mounted sections. Scanning raw data was collected and imported to open resource software ImageJ ( $\mathrm{NIH}$ Image, National Institutes of Health $(\mathrm{NIH})$, Bethesda, Maryland) for brightness and contrast adjustment, followed by compression of the total scanning slices to have the final display.

\section{In situ hybridization of chondrocyte differentiation markers}

257 Once the transplanted graft was localized by EGFP immunohistochemistry, in situ 258 hybridization for chondrocyte markers Prg4, Col10a1, Col2a1 and Col1a1 were performed on consecutive sections. The gene sequences for rat Col1a1 (bone and chondrocyte dedifferentiation marker), Col2a1 (chondrocyte marker) Col10a1 (hypertrophic chondrocyte marker), and Prg4 (superficial chondrocyte marker) were obtained from the UCSC Genome

Browser.

Primers

were

designed

using

Primer-Blast (https://www.ncbi.nlm.nih.gov/tools/primer-blast/), and the resulting amplicons were confirmed by $\mathrm{NCBI}$ Nucleotide Blast. DNA templates for riboprobe transcription were amplified by PCR using the following reagents: Platinum Taq DNA Polymerase (Invitrogen, 
267 proximal tibial epiphyses using a previously described protocol, ${ }^{(37)}$ forward primers

268 containing a T7 promoter (5'-TAATACGACTCACTATAGGGAG-3'), and reverse primers 269 containing a Sp6 promoter (5'-TGGATTTAGGTGACACTATAGAAG-3'): Primer sequences of Rat 270 Col10a1 and Prg4, ${ }^{(38)}$ primer sequences of $\mathrm{Co} / 2 a 1^{(39)}$ were the same as previously illustrated.

271 For Col1a1, forward primer (5'-CATTGGTAACGTTGGTGCTCCT-3') and reverse primer (5'272 TCTCCTCTCTGACCGGGAAGA-3') were designed based on its cDNA (2618-2968 bp of 273 GenBank accession no. BC133728).

274

275 PCR of DNA templates was performed with a 2720 Thermal Cycler (Applied Biosystems, 276 Waltham, MA, USA) using the following parameters: hold at $94^{\circ} \mathrm{C}$ for 5 min, followed by 30 277 cycles of denaturing at $94^{\circ} \mathrm{C}$ for $30 \mathrm{sec}$, annealing at $58^{\circ} \mathrm{C}$ for $30 \mathrm{sec}$, and extending at $72^{\circ} \mathrm{C}$ 278 for $45 \mathrm{sec}$, followed by a final extension at $72^{\circ} \mathrm{C}$ for $3 \mathrm{~min}$. PCR products were purified by 279 agarose gel electrophoresis and a QIAquick Gel Extraction Kit (Qiagen, Hilden, Germany). A 280 second PCR was performed using the same parameters and the products were purified with 281 a QIAquick PCR Purification Kit (Qiagen). Single stranded riboprobes were transcribed with a 282 Roche DIG Labeling Kit (Roche, Basel, Switzerland) incorporating a digoxigenenin (DIG)283 conjugated uracil every 20 to 25 nucleotides. Sp6 polymerase was used for antisense strand riboprobes and $\mathrm{T7}$ polymerase was used for sense strand riboprobes. Riboprobes were purified with Micro Bio-Spin 30 Columns (Bio-Rad, Hercules, CA, USA) and quantified with a NanoDrop Spectrophotometer (Thermo Fisher Scientific).

Non-radioactive digoxigenin in situ hybridization was performed as previously described with slight modifications ${ }^{(40,41)}$. The detailed protocol is available upon request. Briefly, tissue sections were baked at $65^{\circ} \mathrm{C}$ for 1 hour, deparaffinized in xylene, rehydrated through an ethanol series (100\%, 100\%, 95\%, and 70\%), and rinsed in DEPC-treated water. Tissue sections $(6 \mu \mathrm{m})$ were permeabilized with proteinase $K$ at room temperature for $15 \mathrm{~min}$ (10 $\mu \mathrm{g} / \mathrm{ml}$ in PBS, pH7.4), postfixed for 5 min (10\% formalin), and acetylated for 15 min $(0.25 \%$ acetic anhydride in $0.1 \mathrm{M}$ triethanolamine) with each step followed by two 5 min washes in PBS. Prehybridization was carried out at $65^{\circ} \mathrm{C}$ for $2 \mathrm{hrs}$ in hybridization solution (50\% formamide, $10 \mathrm{mM}$ Tris pH7.6, $200 \mu \mathrm{g} / \mathrm{ml}$ Torula yeast RNA, 1X Denhardt's solution, 10\% dextran sulfate, $600 \mathrm{mM} \mathrm{NaCl}, 0.25 \%$ SDS, 1mM EDTA, pH8.0). Hybridization with DIGlabeled riboprobes (100 ng in $100 \mu$ l hybridization solution) was performed at $65^{\circ} \mathrm{C}$ for $4 \mathrm{hs}$. 
299 Posthybridization was carried out by washing with $50 \%$ formamide in $1 \times S S C$ at $65^{\circ} \mathrm{C}$ for 30 $300 \mathrm{~min}$, digesting with RNAse A (20 to $2000 \mu \mathrm{g} / \mathrm{ml}$ in $1 \mathrm{M} \mathrm{NaCl}, 10 \mathrm{mM}$ Tris HCl, 1mM EDTA, $301 \mathrm{pH} 8)$ at $37^{\circ} \mathrm{C}$ for $30 \mathrm{~min}$, and washing in SSC at increasing stringency (4x, 1x, 0.5x, and $\left.0.2 \mathrm{x}\right)$. 302 For detection of hybridized riboprobes, tissue sections were rinsed in MABT (0.1M maleic 303 acid, $0.15 \mathrm{M} \mathrm{NaCl}, 0.1 \% \mathrm{v} / \mathrm{v}$ Tween-20, pH7.5), blocked with 1\% BSA in MABT at room 304 temperature for $30 \mathrm{~min}$, incubated with alkaline phosphatase-conjugated anti-DIG antibody 305 (Roche) in 1\% BSA in MABT at 4 degree for overnight, and then incubated with nitro blue tetrazolium chloride/5-bromo-4-chloro-3-indolyl phosphate (NBT/BCIP) substrates (SigmaAldrich) in NTM $\left(100 \mathrm{mM} \mathrm{NaCl}, 100 \mathrm{mM}\right.$ Tris $\left.\mathrm{pH} 9.5,50 \mathrm{mM} \mathrm{MgCl}_{2}\right)$ at room temperature protected from light for $0.5-4 \mathrm{hrs}$. To mount, tissue sections were rinsed in PBS for $5 \mathrm{~min}$, fixed in $10 \%$ formalin for 20 min, counter stained with nuclear fast red, dehydrated in an ethanol series (70\%, 95\%, and 100\%), cleared in xylene, and mounted with permount. Staining was visualized by scanning the slides under bright field microscopy with a Pannoramic MIDI II 2.0.5 digital scanner (3DHISTECH).

\section{Histomorphometry}

315 High resolution bright-field microscopy images were obtained by using a panoramic MIDI II 2.0.5 digital scanner and analyzed by using compatible CaseViewer software (both from 3DHISTECH). Analysis was carried out in the EGFP positive graft tissues

318 (perichondrium/periosteum). For thickness/height of graft tissues, 10 individual measurements were obtained on GFP immunofluorescence/immunohistochemistry images and then averaged. Scar-tissue thickness was similarly measured on Masson's trichrome stained images for the no transplant control samples. In the transplant and the repair tissues, BrdU labeling and SOX9 positive cell indices were calculated by dividing the number of positive cells in the tissues by the total number of cells. Total number of nuclei in the graft tissues were counted using Image J software. Matrix proteoglycan was assessed by Safranin O staining and the positive area measured using Caseviewer (3DHISTECH). Similarly, in-situ hybridization images were used to quantify the percentage area positive for type I and type II collagen expression. GFP labeling index was calculated by dividing the total number of GFP labeled cells in the subchondral bone by the total number of GFP labeled cells. 
331 Perichondrial and periosteal grafts were investigated for expression of chondrogenic 332 markers. Briefly, after dissection the grafts were lysed in solution C (4M guanidine 333 thiocyanate, $25 \mathrm{mM}$ sodium citrate $\mathrm{pH} 7,0.1 \mathrm{M} \beta$-mercaptoethanol), and stored at $-80^{\circ} \mathrm{C}$ until 334 use. Total RNA (50ng) was extracted and reverse transcribed into cDNA by Superscript 335 Reverse Transcriptase IV (Thermo Fisher Scientific) as previously described ${ }^{(39)}$. Expression of 336 chondrogenic markers (Col2a1, Col10a1, Acan, SOX9 and Prg4) was quantified by real-time 337 PCR ABI Prism 7900 Fast Sequence Detector (Thermo Fisher Scientific, Waltham, MA, USA) 338 (primer sets are listed in Supplementary Table 1). Relative expression was calculated relative 339 to $18 \mathrm{~S}$ rRNA (eukaryotic $18 \mathrm{~S}$ rRNA endogenous control, Thermo Fisher Scientific) by using 340 the formula: $2^{-\Delta \mathrm{Ct}} * 10^{6}$, with $\Delta \mathrm{Ct}$ being target gene expression relative to $18 \mathrm{~S}$.

\section{Statistical analyses}

343 Statistical analysis was carried out using Prism 8.0 software (GraphPad, San Diego, CA, USA).

344 All data are expressed as the mean \pm SEM. Two-way ANOVA with post-surgery time-points 345 and tissues (perichondrium vs. periosteum vs. no transplant) as the two independent 346 variables followed by relevant pair-wise comparisons using Sidak's/Tukey's multiple 347 comparisons tests to determine statistical significance among study groups. Statistical 348 significance was recognized at two-sided p-value less than 0.05 .

\section{RESULTS}

351

352

\section{Perichondrium and periosteum graft transplantation and cell tracing}

Graft recipient animals recovered rapidly after the surgery and were able to ambulate on their hind legs immediately after recovery from anesthesia and were all ambulating normally within 24 hrs including the animals in which the injuries were left without a transplant. None of the animals developed postsurgical infections. Grossly and microscopically, transplanted perichondrium and periosteum allografts appeared to be vital at all postsurgical time-points (Fig. 1,2) without any signs of allograft rejection. The use of donors with ubiquitous EGFP expression (Lew-Tg(CAG-EGFP)YsRrrc) and EGFP-negative recipients enabled tracing of transplanted cells and their progenies at all studied postsurgical time-points by GFP immunofluorescence (Fig. 3a, 3c). 
Perichondrium transplants underwent robust chondrogenesis and differentiated into hyaline cartilage that expanded and were maintained at post-surgery day 112

At post-surgery day 3, perichondrium grafts were fibrous without any cartilaginous areas detectable on Masson's trichrome or Safranin O stained slides (Fig. 2) and did not express Col2a1 (Fig. 4c, 4e), but had high SOX9 expression (Fig. 4a, 4b). In contrast, at 14 days postsurgery the transplanted GFP positive tissue (Fig. 3) consisted almost entirely of light aniline blue and safranin O (Fig. 2) positive cartilaginous tissue and was positive to SOX9 and Col2a1 at the center of the transplant (Fig. 4a, 4e). This hyaline cartilage phenotype was even more clear at 56 days post-surgery with almost all cells of the GFP positive transplant expressing Col2a1 and these high expression levels were largely maintained at post-surgery day 112 (Fig. 3a, 4c, 4e). Conversely, perichondrium transplants expressed Col1a1 intensely in the fibrous layer sutured to the subchondral bone at post-surgery day 3 but were mostly negative in the rest of the transplant and at all subsequent time-points (Fig. 4d, 4e). The thickness of perichondrium and periosteum as well as repair tissues and native articular cartilage all declined with time $(P<0.01$ by ANOVA) with one exception (Fig. 3b). Perichondrium transplant thicknesses increased from day 14 to 56 . This increase was due to an early burst in proliferation (Fig.3d, Supplemental Fig. 1a) followed by hypertrophy. At 14 days post-surgery cells with a hypertrophic appearance and positive to Col10a1 were detected in the central area of the perichondrium transplants (Fig. 2, 5) and also at the bottom of the transplants at post-surgery day 56 and 112 (Fig. 5). Interestingly, at postsurgery day 56 and 112 there were histological signs of active bone remodeling of the hypertrophic cartilage at the bottom of the transplants (Fig. 2a) and there were also GFP positive cells within the bone and bone marrow underneath the transplants (Fig. 3a, 3c). Taken together, these observations demonstrate that transplanted perichondrial cells differentiate into chondrocytes that differentiate into hypertrophic chondrocytes that induce remodeling into bone at the bottom of the transplants. Moreover, GFP positive cells were detected in the subchondral bone suggesting that skeletal progenitor cells of both perichondrium and periosteum are capable of osteoblast and osteocyte differentiation. Interestingly, no hypertrophic differentiation was detected close to the articular surface (Fig. 2 , 5) where chondrocytes, instead, remained small, safranin $O$ negative (Fig. 2a) and eventually oriented tangentially to the surface and expressed Prg4 (Fig. 5b). 
Periosteum transplants developed into a fibrocartilage structure that was thinning with time

Even though SOX9 expression in periosteum is much lower than in perichondrium at day 0 (Supplemental Fig. 2b, 2c), similar to perichondrium transplants, high numbers of SOX9 positive cells (Fig. 4a, 4b) were observed in periosteum transplants at post-surgery day 3. But it still appeared fibrous with no aniline blue stained cartilage matrix and no Safranin 0 (Fig. 2a, 2b; $P<0.001$ by ANOVA) or Col2a1 positive areas in periosteum transplants at this time-point (Fig. 4c ( $P<0.001$ by ANOVA), 4e). By post-surgery day 14 periosteum transplants had also attained safranin $O$ positive areas (Fig 2a, 2b; $P<0.001$ by ANOVA) and were also positive for Col2a1 at the center of the transplants (Fig. 4c, 4e). However, they still had a more fibrocartilage-like appearance and were also positive for Col1a1 (Fig. 4d, 4e) and had less SOX9 expressing cells (Fig. 4a, 4b). In contrast to the perichondrium transplants, periosteum transplant thickness continuously declined (Fig. 3b; $P<0.01$ by ANOVA) and lost some of their cartilaginous appearance and cartilage marker expression, i.e. decreased expression of Col2a1 (Fig. 4c ( $P<0.01$ by ANOVA), 4e) and Safranin O staining (Fig 2a, 2b; $P<$ 0.001 by ANOVA). In addition, Col1a1 expression could be detected at all time-points while mostly absent in the transplanted perichondrium (Fig. 4d, 4e). Therefore, injuries repaired with periosteum were thinner (Fig. $3 \mathrm{~b} ; P=0.0015$ by ANOVA) and had a less cartilaginous appearance than those repaired with perichondrium (Fig. 2, 4). Periosteum transplants were however thicker and had a more cartilaginous appearance than the repair tissue of no transplant controls at the later time-points (Fig. 2, 4). Interestingly, GFP positive periosteum cells did not differentiate into Prg4 expressing chondrocytes at the articular surface (Fig. 5b), and were to a larger extent incorporated into the underlying bone than cells derived from perichondrium transplants (Fig. 3a, 3c $(P<0.05$ by ANOVA)).

Cartilage injuries not covered with a transplant healed quickly and provided similar short term, but poor long-term results

421 Defects left without a transplant were completely filled by fibrous repair tissue already at postoperative day 3 with a macroscopic appearance at least as good as the perichondrium and periosteum filled defects (Fig. 1). Interestingly, the upper part of the tissue filling the defect appeared to be a fibrous sheet continuous with the synovial membrane on one side, 
426 2), whereas at the bottom, there were no sharp border to the underlying bone marrow (Fig.

427 2). Despite having similar levels of SOX9 positive cells at post-surgery day 3 (Fig. 4a , 4b,

428 Supplemental Fig. 1b), repair tissue never attained a hyaline cartilage appearance and 429 remained positive for Col1a1 by in situ hybridization and negative to safranin 0 staining, as 430 well as for Col2a1 and Col10a1 at post-surgery day 14 (Fig. 2, 4, 5) and also at all subsequent 431 time-points. In contrast to perichondrium, but similar to periosteum, the repair tissue 432 thickness declined continuously from post-surgery day 3 to 112 (Fig. 3b; $P=0.0015$ by 433 ANOVA) at which point there was only a thin layer of translucent fibrocartilage covering the 434 subchondral bone (Fig. 1-3). The repair tissue was negative for Prg4 expression at 3- and 14435 days post-surgery, but an increasing number of Prg4 positive cells were detected at the 436 surface on post-surgery days 56 and 112 (Supplemental Fig. 2a), suggesting possible 437 infiltration of Prg4 positive cells from the surrounding articular cartilage and/or synovial 438 tissue.

439

DISCUSSION

441 There is a lack of suitable tissues that can be used to resurface injured and eroded articular 442 cartilage. Rib perichondrium has been used clinically as a tissue source, sometimes with 443 favorable long-term results ${ }^{(36,42)}$. However, the quality of the resulting joint surfaces and the 444 contribution of the transplanted tissues have not been investigated in detail. We here used 445 transgenic rats with ubiquitous EGFP expression allowing for tracing of transplanted cells. 446 We found that perichondrium transplants formed durable hyaline cartilage tissue with high 447 proteoglycan content that filled out the articular cartilage defects including the area of 448 active remodeling in the subchondral bone, and with time attained structure and 449 chondrocyte marker expression patterns similar to the surrounding articular cartilage. This 450 finding is consistent with the favorable results sometimes reported using perichondrium to 451 resurface injured joints ${ }^{(36,42,43)}$ and taken together indicate that rib perichondrium is a 452 suitable tissue to repair injured joints.

453

454 The levels of SOX9 expression was low in the harvested periosteum compared to 455 perichondrium samples but was then dramatically induced to reach level similar to 456 perichondrium by post-surgery day 3 . The increase of SOX9 was sufficient to induce a 457 transient chondrogenic differentiation program of osteochondral progenitors in the 
458 periosteum transplants with large parts of the periosteum cells being Col2a1 positive and 459 surrounded by matrix with high proteoglycan content 14 days after the surgeries. However, 460 in contrast to the perichondrium, the transplanted periosteum tissues expressed Col1a1 at 461 all time-points and were continuously thinning and lost SOX9 expressing cells and 462 subsequent Col2a1 expression and proteoglycan content after post-surgery day 14 time463 point. Consequently, at post-surgery day 56 and 112 the injuries repaired with periosteum 464 transplants had depressed articular surfaces and an overall histological appearance and 465 chondrocyte marker expression pattern in between the no transplant controls and the 466 perichondrium transplants. The early increase of SOX9 expression was thus not sufficient to 467 induce a lasting chondrogenic program in the periosteum transplants and as the SOX9 468 expression declined, the cells lost their chondrogenic phenotype and instead differentiated 469 towards osteoblasts. These findings confirm and extend previous studies suggesting that the 470 osteochondroprogenitor cells of periosteum are less chondrogenic and more osteogenic 471 than perichondrial osteochondroprogenitors when placed ectopically in the synovial 472 microenvironment ${ }^{(44-46)}$. This is also consistent with studies that have demonstrated mostly 473 poor outcomes when periosteum is used as a tissue source for articular cartilage repair ${ }^{(47,48)}$. 474 The findings are also largely compatible with the physiological role of the periosteum during appositional growth of bones as well as during fracture repair ${ }^{(49)}$.

477 A chondrogenic program was induced in perichondrium and partially also in periosteum 478 placed ectopically at the joint surface. This also occurs if perichondrium is placed in the 479 subcutaneous space ${ }^{(50,51)}$, but not when perichondrium is ectopically placed on muscle or in 480 the liver unless it is exposed to blood ${ }^{(30,44,52)}$. Our findings taken together with these 481 previous findings may suggest that the synovial microenvironment contains one or several 482 factors that act on perichondrial cells to induce chondrogenic differentiation. In addition, we 483 found that hypertrophic differentiation occurred first at the center and later at the bottom 484 of the transplant, but never at the surface, and also that Prg4 positive cells were detected at 485 the surface of the formed cartilage at the latest time-point. This observation might suggest 486 that the cartilage formed from the perichondrium transplant has an inherent chondrogenic 487 program producing a cartilaginous structure with chondrocyte differentiation marker 488 expression profile similar to articular cartilage. However, a more likely explanation would be 
489 that the perichondrium has an inherent chondrogenic program that is modified by the local 490 microenvironment of the joint. Specifically, that the joint microenvironment may inhibit 491 hypertrophic differentiation and promote differentiation towards the superficial layer 492 chondrocyte phenotype ${ }^{(53,54)}$. This hypothesis would explain our observation that the newly 493 formed chondrocytes of the perichondrium underwent hypertrophic differentiation only some distance away from the surface, but never close to the surface where chondrocytes instead remained small and eventually attained a superficial chondrocyte-like phenotype.

Articular cartilage injuries left without a transplant were quickly filled by fibrous tissue that appeared to restore joint function but never differentiated into hyaline cartilage. This is consistent with the current thinking that full thickness cartilage injuries are repaired presumably by a blood clot from the bone marrow, which is organized into a fibrocartilage tissues that, in the long-term, leave the injured joints susceptible to future degeneration and osteoarthritis development. However, macroscopic and microscopic observations in our study suggest that in addition to the formation of a blood clot, rapid synovial invasion covering the blood clot and the injury also occurs. However, there were almost no Prg4 positive cells at the injury site at post-surgery day 3 and 14 . This could be due to a loss of Prg4 expression in synovial cells as they were attracted to the injury site, or that only Prg4 negative synovial tissue cells were attracted to the injury site. Other options can be that the 508 injury site was mostly filled-up by bone marrow cells and that the blood clot did not only fill up the injury but also became continuous with the synovial membrane during the early healing phase. Further studies are needed to address these possibilities as we were not able

511 to definitely distinguish between these options in the current study. It is interesting that a rapid and efficient repair of cartilage injuries has evolved, but the repair tissue never forms a durable hyaline cartilage that fills the injury, forming instead only a thinning layer of

514 fibrocartilage that leaves the injured joint susceptible to osteoarthritis development. This 515 may be due to the lack of suitable skeletal stem cells with chondrogenic potential and/or 516 that the local microenvironment prevents chondrogenic differentiation of available stem 517 cells. A recent study indicates that this limitation of the endogenous repair tissue may be 518 overcome if the synovial microenvironment is modified. In the study, Murphy et al showed 519 that co-delivery of BMP2 and a soluble VEGFR1 in knee joints at microfracture surgery was 
520 sufficient to induce SOX9 expression and formation of hyaline cartilage in the repair tissue

521 (55)

522

523 Free, autologous perichondrium transplants have been used successfully, but with variable

524 results, to repair a variety of articular cartilage injuries ${ }^{(32-35,56,57)}$. We used a rat model

525 allowing for tracing of transplanted cells and found that surfaces repaired with

526 perichondrium were exclusively made up of transplanted cells and their progenies even after

527112 days, thus addressing the long-standing question whether perichondrium itself have the

528 capacity to regenerate a new joint surface or if it merely attracts invasion of chondrogenic

529 stem cells from the bone marrow, synovial membrane or other surrounding tissues ${ }^{(21)}$,

530 which in turn regenerate the surface. The finding that the transplanted perichondrium

531 expanded and filled the articular cartilage defects and that the surfaces seemed to

532 differentiate and mold to form an articular cartilage-like covering of the subchondral bone, is

533 consistent with clinical observations that perichondrium transplantation in many cases can

534 produce favorable long-term results if transplant detachment and other potential short-term

535 complications are avoided ${ }^{(36,42)}$.

536

537 In summary, rib perichondrium transplanted to full-thickness articular cartilage defects

538 produced hyaline cartilage that filled out the defects and with time differentiated and

539 molded to attain a structure and chondrocyte marker expression pattern similar to the

540 surrounding articular cartilage. In contrast, transplanted periosteum resulted in a thinning

541 layer of fibrocartilage covering a crater-like defect that with time provided more cells into

542 the underlying bone than the articular cartilage itself. These findings indicate that

543 perichondrium, but not periosteum, is a suitable tissue-source for repair of articular cartilage

544 defects, resurfacing of injured joints, and tissue engineering of articular cartilage. In

545 addition, we suggest that the most likely explanation for the absence of hypertrophic

546 differentiation in the superficial cell layers and their differentiation towards superficial-like

547 cells is that the synovial microenvironment inhibits chondrocyte hypertrophy and promote

548 articular cartilage differentiation. Further studies exploring the role of the synovial joint

549 microenvironment as well as the possibilities of using perichondrium as a tissue source for

550 articular cartilage repair, resurfacing, and articular cartilage tissue engineering are

551 warranted. 


\section{Acknowledgements}

554 The authors acknowledge expert advice from Dr. Phillip Newton in Department of Women's 555 and Children's Health at Karolinska Institutet for Safranin-O staining and for 556 immunofluorescence confocal microscopy. This study was supported by grants from the 557 Swedish Research Council (project K2015-54X-22 736-01-4 \& 2015-02227), the Swedish 558 Governmental Agency for Innovation Systems (Vinnova) (2014-01438), Marianne and 559 Marcus Wallenberg Foundation, the Stockholm County Council, the Uppsala County Council, 560 Byggmästare Olle Engkvist Stiftelse, the Swedish Society of Medicine, Novo Nordisk 561 Foundation, Erik och Edith Fernström Foundation for Medical Research, HKH Kronprinsessan 562 Lovisas förening för barnasjukvård, Sällskapet Barnavård, Stiftelsen Frimurare Barnhuset i 563 Stockholm, Promobilia, Nyckelfonden, and Karolinska Institutet, Stockholm, Sweden, and 564 Örebro University, Örebro, Sweden.

565

Author contributions

567 O.N. and T.V. conceived the project and designed the study. Z.D., D.M., M.B., A.B., A.G., T.V. 568 L.O., and O.N. performed experiments, O.N., T.V., Z.D., and D.M. analyzed data and wrote the manuscript. All authors read and approved the final draft.

\section{References}

572

573

574

575

576

577

578

579

580

581

582

583

584

585

586

587

588
1. Kronenberg HM. Developmental regulation of the growth plate. Nature. May 15 2003;423(6937):332-6. Epub 2003/05/16.

2. Gerber HP, Vu TH, Ryan AM, Kowalski J, Werb Z, Ferrara N. VEGF couples hypertrophic cartilage remodeling, ossification and angiogenesis during endochondral bone formation. Nat Med. Jun 1999;5(6):623-8. Epub 1999/06/17.

3. Patel JM, Dunn MG. Cartilage tissue engineering. Regenerative Engineering of Musculoskeletal Tissues and Interfaces2015. p. 135-60.

4. Ono N, Balani DH, Kronenberg HM. Stem and progenitor cells in skeletal development. Curr Top Dev Biol. 2019;133:1-24. Epub 2019/03/25.

5. Kronenberg HM. The role of the perichondrium in fetal bone development. Ann N Y Acad Sci. Nov 2007;1116:59-64. Epub 2007/12/18.

6. Ono N, Kronenberg HM. Bone repair and stem cells. Curr Opin Genet Dev. Oct 2016;40:103-7. Epub 2016/07/12.

7. Colnot C. Skeletal cell fate decisions within periosteum and bone marrow during bone regeneration. J Bone Miner Res. Feb 2009;24(2):274-82. Epub 2008/10/14. 
589 8. Lefebvre V, Bhattaram P. Vertebrate skeletogenesis. Curr Top Dev Biol. 2010;90:291-

590

591

592

593

594

595

596

597

598

599

600

601

602

603

604

605

606

607

608

609

610

611

612

613

614

615

616

617

618

619

620

621

622

623

624

625

626

627

628

629

630

631

632

633

634

635

636

637

638

639

640

641

642
317. Epub 2010/08/10.

9. Shwartz Y, Viukov S, Krief S, Zelzer E. Joint Development Involves a Continuous Influx of Gdf5-Positive Cells. Cell Rep. Jun 21 2016;15(12):2577-87. Epub 2016/06/14.

10. Khan IM, Redman SN, Williams R, Dowthwaite GP, Oldfield SF, Archer CW. The development of synovial joints. Curr Top Dev Biol. 2007;79:1-36. Epub 2007/05/15.

11. Hyde G, Boot-Handford RP, Wallis GA. Col2a1 lineage tracing reveals that the meniscus of the knee joint has a complex cellular origin. J Anat. Nov 2008;213(5):531-8. Epub 2008/11/19.

12. Koyama E, Shibukawa Y, Nagayama M, Sugito H, Young B, Yuasa T, et al. A distinct cohort of progenitor cells participates in synovial joint and articular cartilage formation during mouse limb skeletogenesis. Dev Biol. Apr 1 2008;316(1):62-73. Epub 2008/02/26.

13. Pacifici M, Koyama E, Iwamoto M. Mechanisms of synovial joint and articular cartilage formation: recent advances, but many lingering mysteries. Birth Defects Res C Embryo Today. Sep 2005;75(3):237-48. Epub 2005/09/28.

14. Kozhemyakina E, Lassar AB, Zelzer E. A pathway to bone: signaling molecules and transcription factors involved in chondrocyte development and maturation. Development. Mar 1 2015;142(5):817-31. Epub 2015/02/26.

15. Li L, Newton PT, Bouderlique T, Sejnohova M, Zikmund T, Kozhemyakina E, et al. Superficial cells are self-renewing chondrocyte progenitors, which form the articular cartilage in juvenile mice. FASEB J. Mar 2017;31(3):1067-84. Epub 2016/12/15.

16. Chijimatsu R, Saito T. Mechanisms of synovial joint and articular cartilage development. Cell Mol Life Sci. Oct 2019;76(20):3939-52. Epub 2019/06/16.

17. Buckwalter JA. Were the Hunter brothers wrong? Can surgical treatment repair articular cartilage? lowa Orthop J. 1997;17:1-13. Epub 1997/01/01.

18. Mankin HJ. The response of articular cartilage to mechanical injury. J Bone Joint Surg Am. Mar 1982;64(3):460-6. Epub 1982/03/01.

19. Hunziker EB, Lippuner K, Keel MJ, Shintani N. An educational review of cartilage repair: precepts \& practice--myths \& misconceptions--progress \& prospects. Osteoarthritis Cartilage. Mar 2015;23(3):334-50. Epub 2014/12/24.

20. Hunziker EB, Rosenberg LC. Repair of partial-thickness defects in articular cartilage: cell recruitment from the synovial membrane. J Bone Joint Surg Am. May 1996;78(5):721-33. Epub 1996/05/01.

21. Hunziker EB. Articular cartilage repair: basic science and clinical progress. A review of the current status and prospects. Osteoarthritis Cartilage. Jun 2002;10(6):432-63. Epub $2002 / 06 / 12$.

22. Lynch TS, Patel RM, Benedick A, Amin NH, Jones MH, Miniaci A. Systematic review of autogenous osteochondral transplant outcomes. Arthroscopy. Apr 2015;31(4):746-54. Epub 2015/01/27.

23. Angele P, Niemeyer P, Steinwachs M, Filardo G, Gomoll AH, Kon E, et al. Chondral and osteochondral operative treatment in early osteoarthritis. Knee Surg Sports Traumatol Arthrosc. Jun 2016;24(6):1743-52. Epub 2016/02/29.

24. Campbell AB, Pineda M, Harris JD, Flanigan DC. Return to Sport After Articular Cartilage Repair in Athletes' Knees: A Systematic Review. Arthroscopy. Apr 2016;32(4):651-68 e1. Epub 2015/11/04.

25. Brittberg M, Lindahl A, Nilsson A, Ohlsson C, Isaksson O, Peterson L. Treatment of deep cartilage defects in the knee with autologous chondrocyte transplantation. N Engl J Med. Oct 6 1994;331(14):889-95. Epub 1994/10/06.

26. O'Driscoll SW, Fitzsimmons JS. The role of periosteum in cartilage repair. Clin Orthop Relat Res. Oct 2001(391 Suppl):S190-207. Epub 2001/10/18.

27. Skoog T, Johansson SH. The formation of articular cartilage from free perichondrial grafts. Plast Reconstr Surg. Jan 1976;57(1):1-6. Epub 1976/01/01.

28. Ohlsen L, Skoog T, Sohn SA. The pathogenesis of cauliflower ear. An experimental study in rabbits. Scand J Plast Reconstr Surg. 1975;9(1):34-9. Epub 1975/01/01. 
643 29. Engkvist O, Johansson SH, Ohlsen L, Skoog T. Reconstruction of articular cartilage using

644

645

646

647

648

649

650

651

652

653

654

655

656

657

658

659

660

661

662

663

664

665

666

667

668

669

670

671

672

673

674

675

676

677

678

679

680

681

682

683

684

685

686

687

688

689

690

691

692

693

694

695 autologous perichondrial grafts. A preliminary report. Scand J Plast Reconstr Surg. 1975;9(3):203-6. Epub 1975/01/01.

30. Ohlsen L. Cartilage formation from free perichondrial grafts: an experimental study in rabbits. Br J Plast Surg. Jul 1976;29(3):262-7. Epub 1976/07/01.

31. Engkvist O, Ohlsen L. Reconstruction of articular cartilage with free autologous perichondrial grafts. An experimental study in rabbits. Scand J Plast Reconstr Surg. 1979;13(2):269-74. Epub 1979/01/01.

32. Engkvist O, Johansson SH. Perichondrial arthroplasty. A clinical study in twenty-six patients. Scand J Plast Reconstr Surg. 1980;14(1):71-87. Epub 1980/01/01.

33. Seradge H, Kutz JA, Kleinert HE, Lister GD, Wolff TW, Atasoy E. Perichondrial resurfacing arthroplasty in the hand. J Hand Surg Am. Nov 1984;9(6):880-6. Epub 1984/11/01.

34. Pastacaldi P. Perichondrial wrist arthroplasty--a follow-up study in 17 rheumatoid patients. Ann Plast Surg. Aug 1982;9(2):146-51. Epub 1982/08/01.

35. Katsaros J, Milner R, Marshall NJ. Perichondrial arthroplasty incorporating costal cartilage. J Hand Surg Br. Apr 1995;20(2):137-42. Epub 1995/04/01.

36. Muder D, Nilsson 0 , Vedung T. Reconstruction of finger joints using autologous rib perichondrium - an observational study at a single Centre with a median follow-up of 37 years. BMC Musculoskelet Disord. Apr 29 2020;21(1):278. Epub 2020/05/01.

37. Nilsson O, Parker EA, Hegde A, Chau M, Barnes KM, Baron J. Gradients in bone morphogenetic protein-related gene expression across the growth plate. J Endocrinol. Apr 2007;193(1):75-84. Epub 2007/04/03.

38. Chau M, Lui JC, Landman EB, Spath SS, Vortkamp A, Baron J, et al. Gene expression profiling reveals similarities between the spatial architectures of postnatal articular and growth plate cartilage. PLoS One. 2014;9(7):e103061. Epub 2014/07/30.

39. Spath SS, Andrade AC, Chau M, Baroncelli M, Nilsson O. Evidence That Rat Chondrocytes Can Differentiate Into Perichondrial Cells. JBMR Plus. Nov 2018;2(6):351-61. Epub 2018/11/22.

40. Bandyopadhyay A, Kubilus JK, Crochiere ML, Linsenmayer TF, Tabin CJ. Identification of unique molecular subdomains in the perichondrium and periosteum and their role in regulating gene expression in the underlying chondrocytes. Dev Biol. Sep 1 2008;321(1):162-74. Epub 2008/07/08.

41. Lui JC, Chau M, Chen W, Cheung CS, Hanson J, Rodriguez-Canales J, et al. Spatial regulation of gene expression during growth of articular cartilage in juvenile mice. Pediatr Res. Mar 2015;77(3):406-15. Epub 2014/12/19.

42. Muder D, Hailer NP, Vedung T. Two-component surface replacement implants compared with perichondrium transplantation for restoration of Metacarpophalangeal and proximal Interphalangeal joints: a retrospective cohort study with a mean follow-up time of 6 respectively 26 years. BMC Musculoskelet Disord. Oct 7 2020;21(1):657. Epub 2020/10/09.

43. Bouwmeester PS, Kuijer R, Homminga GN, Bulstra SK, Geesink RG. A retrospective analysis of two independent prospective cartilage repair studies: autogenous perichondrial grafting versus subchondral drilling 10 years post-surgery. J Orthop Res. Mar 2002;20(2):267-73. Epub 2002/04/02.

44. Skoog V, Widenfalk B, Ohlsen L, Wasteson A. The effect of growth factors and synovial fluid on chondrogenesis in perichondrium. Scand J Plast Reconstr Surg Hand Surg. 1990;24(2):89-95. Epub 1990/01/01.

45. Ritsila V, Alhopuro S, Rintala A. Bone formation with free periosteum. An experimental study. Scand J Plast Reconstr Surg. 1972;6(1):51-6. Epub 1972/01/01.

46. Ritsila V. Regeneration of articular cartilage defects with free perichondrial grafts. Clinical Orthopaedics and Related Research. 1994;302:259-65.

47. Gooding CR, Bartlett W, Bentley G, Skinner JA, Carrington R, Flanagan A. A prospective, randomised study comparing two techniques of autologous chondrocyte implantation 
for osteochondral defects in the knee: Periosteum covered versus type I/III collagen covered. Knee. Jun 2006;13(3):203-10. Epub 2006/04/29.

48. McCarthy HS, Roberts S. A histological comparison of the repair tissue formed when using either Chondrogide((R)) or periosteum during autologous chondrocyte implantation. Osteoarthritis Cartilage. Dec 2013;21(12):2048-57. Epub 2013/10/29.

49. van Gastel N, Stegen S, Eelen G, Schoors S, Carlier A, Daniels VW, et al. Lipid availability determines fate of skeletal progenitor cells via SOX9. Nature. Mar 2020;579(7797):1117. Epub 2020/02/28.

50. ten Koppel PG, van Osch GJ, Verwoerd CD, Verwoerd-Verhoef HL. Efficacy of perichondrium and a trabecular demineralized bone matrix for generating cartilage. Plast Reconstr Surg. Nov 1998;102(6):2012-20; discussion 21. Epub 1998/11/12.

51. Kagimoto S, Takebe T, Kobayashi S, Yabuki Y, Hori A, Hirotomi $\mathrm{K}$, et al. Autotransplantation of Monkey Ear Perichondrium-Derived Progenitor Cells for Cartilage Reconstruction. Cell Transplant. 2016;25(5):951-62. Epub 2016/02/18.

52. Sari A, Tuncer S, Ayhan S, Elmas C, Ozogul C, Latifoglu O. What wrapped perichondrial and periosteal grafts offer as regenerators of new tissue. J Craniofac Surg. Nov 2006;17(6):1137-43. Epub 2006/11/23.

53. Dou Z. Growth plate cartilage transplanted to the articular surface remodels into articular-like cartilage in a process promoted by the synovial joint microenvironment. Bone Report. 2020;13S:Abstract 100410.

54. Baroncelli M. Synovial cells secrete a temperature-stable protein that inhibits hypertrophic differentiation and induces articular cartilage differentiation of chondrocytes in vitro. Bone Reports. 2020;13S:Abstract 100665.

55. Murphy MP, Koepke LS, Lopez MT, Tong X, Ambrosi TH, Gulati GS, et al. Articular cartilage regeneration by activated skeletal stem cells. Nat Med. Oct 2020;26(10):158392. Epub 2020/08/19.

56. Bouwmeester SJ, Beckers JM, Kuijer R, van der Linden AJ, Bulstra SK. Long-term results of rib perichondrial grafts for repair of cartilage defects in the human knee. Int Orthop. 1997;21(5):313-7. Epub 1997/01/01.

57. Vedung T, Vinnars B. Resurfacing the distal radioulnar joint with rib perichondrium-a novel method. J Wrist Surg. Aug 2014;3(3):206-10. Epub 2014/08/07.

\section{FIGURE LEGENDS}

\section{Figure 1. Experimental design and articular surfaces of cartilage defects repaired with} perichondrium or periosteum transplants or left untreated. Perichondrium and periosteum grafts were harvested from EGFP positive Lewis (inbred) rats and transplanted into fullthickness cartilage injuries at the distal femoral intercondylar groove in wild-type littermates (a). At post-surgery day 3,14, 56, and 112, femoral epiphyses were collected, fixed overnight in formalin, decalcified in (EDTA, 15\%). Low power microphotographs were captured using a Leica M320 dental microscope (b). Scale bar represents $1000 \mu \mathrm{m}$. 
739 Representative microphotographs of Masson Trichrome and Safranin-O (high power) stained 740 tissue sections of distal femur epiphyses from perichondrium transplanted $(n=3)$, 741 periosteum transplanted $(n=3)$ and no transplant control ( $n=3$ except for day 14 post742 surgery $(n=2)$ ) rats at $3,14,56,112$ days post-surgery displayed at low (Masson Trichrome) 743 and high (Masson Trichrome and Safranin-O) power magnification (a). Safranin 0 index was 744 calculated by dividing the safranin 0 positive area by total area of grafts or repair tissue 745 respectively at 3, 14, 56 and 112 days post-surgery (b). Safranin-O is higher in perichondrium than in periosteum and repair tissue $(P<0.001$ by ANOVA).

$(* *)$ compared to perichondrium group; $* * P<0.01$. Scale bar represents $500 \mu \mathrm{m}$.

Figure 3. Tracing of transplant derived cells, thickness of grafts and repair tissue, and cell proliferation.

Transplant derived cells were visualized using EGFP immunofluorescence on frozen sections of distal epiphyses at post-surgery day 3, 14, 56 and 112. Representative immunofluorescence images were aligned with corresponding Masson's trichrome stained tissue sections (a). Thickness of grafts and repair tissue (b). Thickness was measured perpendicular to the joint surface at 10 different locations spreading evenly over each graft/repair tissue and averaged. Perichondrium transplants were thicker than periosteum transplants and repair tissue $(P<0.001$ by ANOVA). Subchondral GFP positive cell index was calculated by dividing the number of positive cells by the total number of cells in the subchondral bone cell compartment $(\mathbf{c})$, and it was higher in periosteum group than in perichondrium group $(\mathrm{P}<0.05$ by ANOVA). Proliferation rate in each transplant and repair tissue was assessed by BrdU labeling and immunohistochemistry. The number of BrdU labelled cells within the graft or repair tissue was divided by the total number of cells to produce BrdU indices (d). Cell proliferation declined with time $\left(\mathrm{P}<0.05\right.$ by ANOVA). $\left({ }^{*}\right)$ compared to repair tissue group; $* P<0.05, * * P<0.01$. Scale bar represents $500 \mu \mathrm{m}$.

Figure 4. SOX9 immunofluorescence and collagen type I and II in situ hybridization of 
768 SOX9 was targeted by immunofluorescence or immunohistochemistry in frozen or paraffin 769 sections of distal epiphyses at post-surgery day 3, 14, 56 and 112. Representative 770 immunofluorescence images of perichondrium and periosteum transplant groups were 771 displayed with grafts indicated by white dotted lines (a). SOX9 positive cell index was 772 calculated by dividing the number of SOX9 positive cells by total number of cells within 773 grafts or repair tissue at 3, 14, 56, and 112 days post-surgery (b), and was similar in all 774 groups at post-surgery day 3 , but then decreased in the periosteum transplant and no transplant groups $(P<0.01$ by ANOVA). Col2a1 and Col1a1 mRNA were visualized (purple coloration) with non-radioactive digoxigenin labeled riboprobes in consecutive paraffin sections of distal femoral epiphyses. Col2a1 and Col1a1 positive area percentage was calculated by dividing their positive areas by total area of transplants or repair tissue respectively and multiplied by 100 (c, d). All samples were negative to Col2a1 at post-surgery day 3 , increased to day 14 in both perichondrium and periosteum, and then remained high in perichondrium at post-surgery day 56 and 112, but were mostly negative in periosteum transplants (c; $P<0.05$ and $P<0.001$ for time and tissue, respectively, by ANOVA). Perichondrium transplants were positive to Col1a1 in situ hybridization at the bottom of the transplants (fibrous layer of perichondrium) at post-surgery day 3 and 14 but then mostly negative at post-surgery day 56 and 112, whereas periosteum had a high level of Col1a1 expression at the later time-points (d, e). Representative in situ hybridization images of perichondrium transplanted, periosteum transplanted and no transplant control groups were displayed in low (Col2a1) and high power (Col2a1 (upper insert) \& Col1a1 (lower insert)) magnification (e). $\left({ }^{*}\right)$ Compared to perichondrium transplant group; ${ }^{*} P<0.05 ; * * P<$ $0.01, * * * P<0.001$. Scale bar represents $500 \mu \mathrm{m}$.

Figure 5. Col10a1 and Prg4 in situ hybridization of perichondrium and periosteum grafts and repair tissue.

794 Representative Col10a1 in situ hybridization microphotographs of perichondrium 795 transplanted, periosteum transplanted and no transplant control groups at different post796 surgery time-points displayed at low and high power magnification (a). Positive Col10a1 797 signal (purple coloration) was visualized at the center of perichondrium transplants at post- 
798 surgery day 14 , at the center and bottom of the transplants at day 56 , and only at the 799 bottom of the perichondrium transplants at post-surgery day 112 . GFP 800 immunohistochemistry and Prg4 in situ hybridization was performed on consecutive 801 sections to allow for indirect co-localization of GFP protein and Prg4 mRNA here shown in 802 high power to visualize Prg4 expression in the most superficial cell layers of perichondrium, 803 but not periosteum, grafts at post-surgery day 112 (b). Scale bar represents $500 \mu \mathrm{m}$.

804

805 Supplemental Figure 1. Cell proliferation and SOX9 immunofluorescence in repair tissue 806 group

807 Cell proliferation was assessed by BrdU labeling followed by BrdU immunohistochemistry on 808 paraffin sections of distal epiphyses from grafts and repair tissues at post-surgery day 3, 14, 80956 and 112. Representative immunohistochemistry high power magnification images were 810 aligned with lower power magnification Masson's trichrome staining images from 811 consecutive sections (a). SOX9 expression was visualized by immunofluorescence on frozen

812 sections of distal femoral epiphyses. Representative SOX9 immunofluorescence images of 813 repair tissue at post-surgery day 3,14, 56 and 112 (b). Scale bar represents $500 \mu \mathrm{m}$.

814

815 Supplemental Figure 2. Prg4 in situ hybridization of perichondrium, periosteum grafts and 816 repair tissue at post-surgery and markers expression in grafts at day 0.

817 Representative Prg4 in situ hybridization images of perichondrium transplanted, periosteum 818 transplanted and no transplant control groups displayed at low and high power 819 magnification (a). The relative mRNA expression of Col2a1, Col10a1, SOX9, ACAN, and Prg4 820 in perichondrium and periosteum pieces ( 3 technical replicates performed in each group 821 with tissue pieces from same donor animal) assessed by real-time PCR at day 0 (b). 822 Representative Masson's trichrome staining and SOX9 immunohistochemistry images of 823 perichondrium and periosteum transplant sections at day 0 (c). Scale bar represents $200 \mu m$ 824 in low and $20 \mu \mathrm{m}$ in high magnification images. 


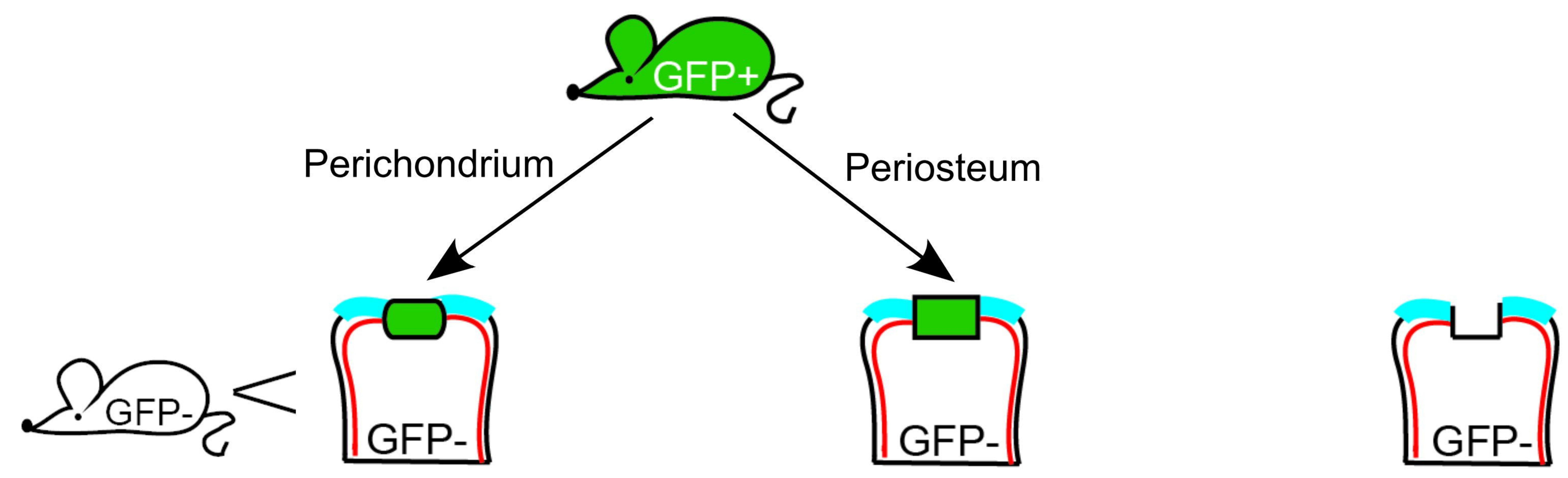

B
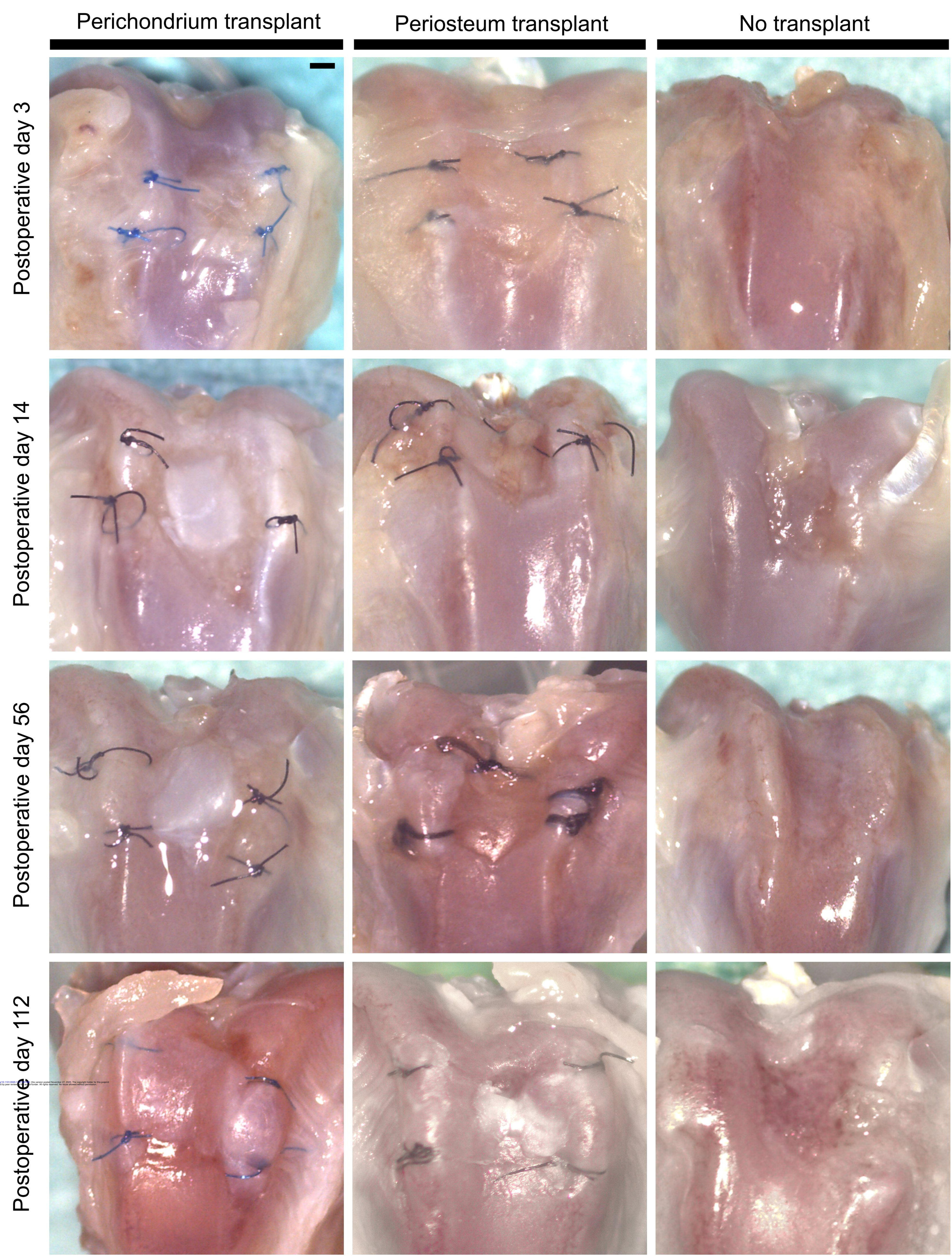

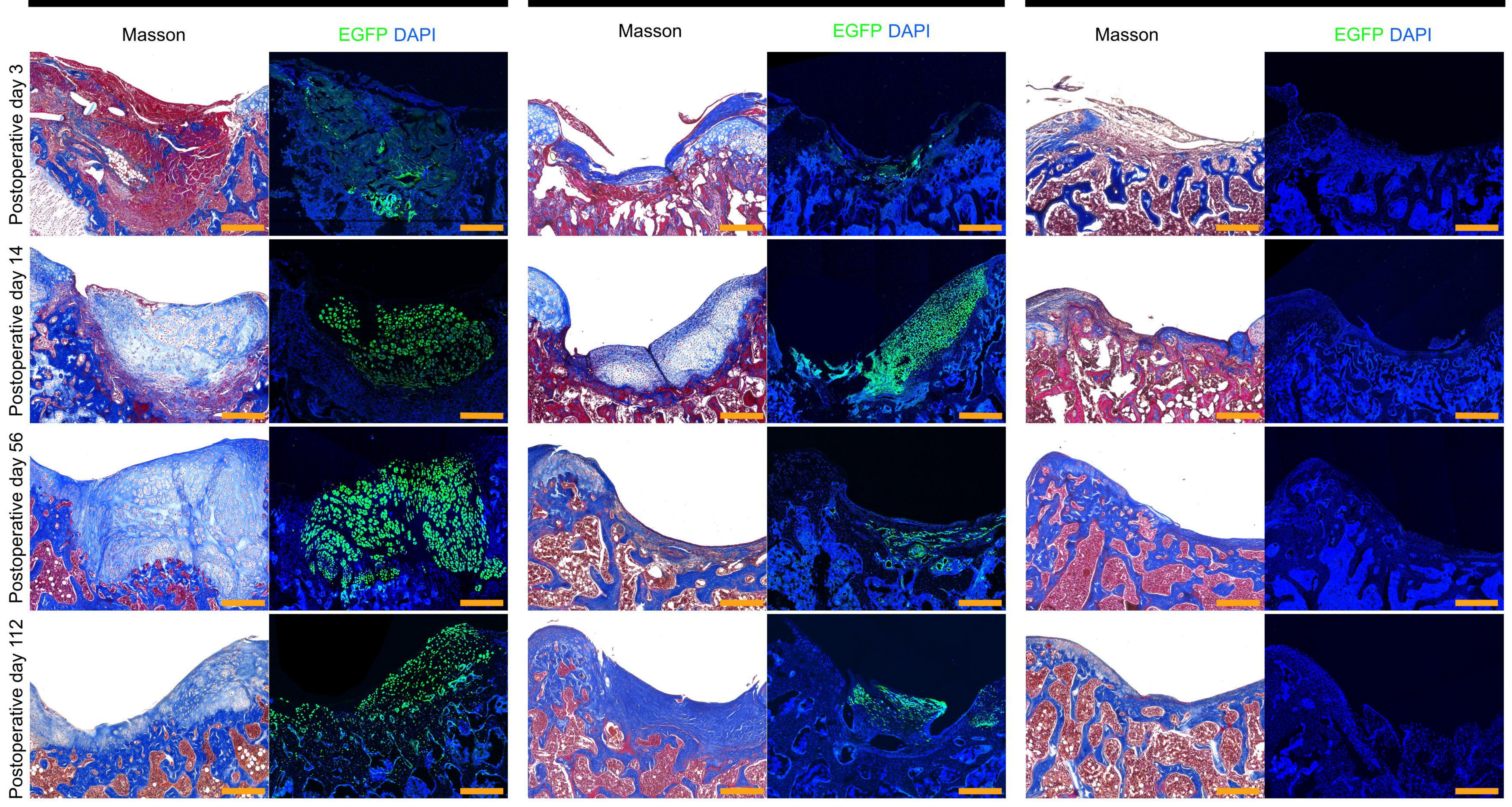

B

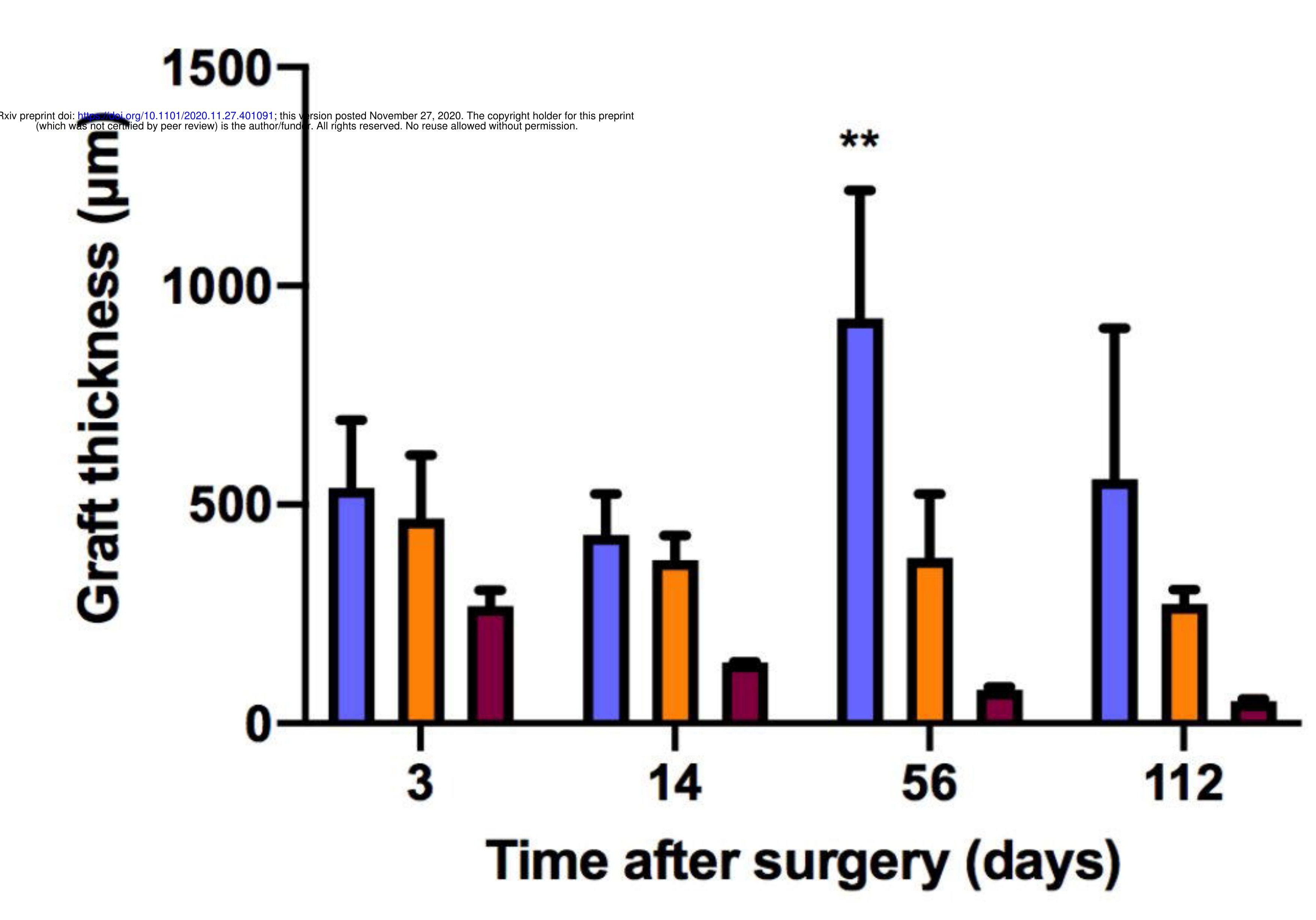

Perichondrium $\square$ Periosteum $\square$ Repair Tissue
C

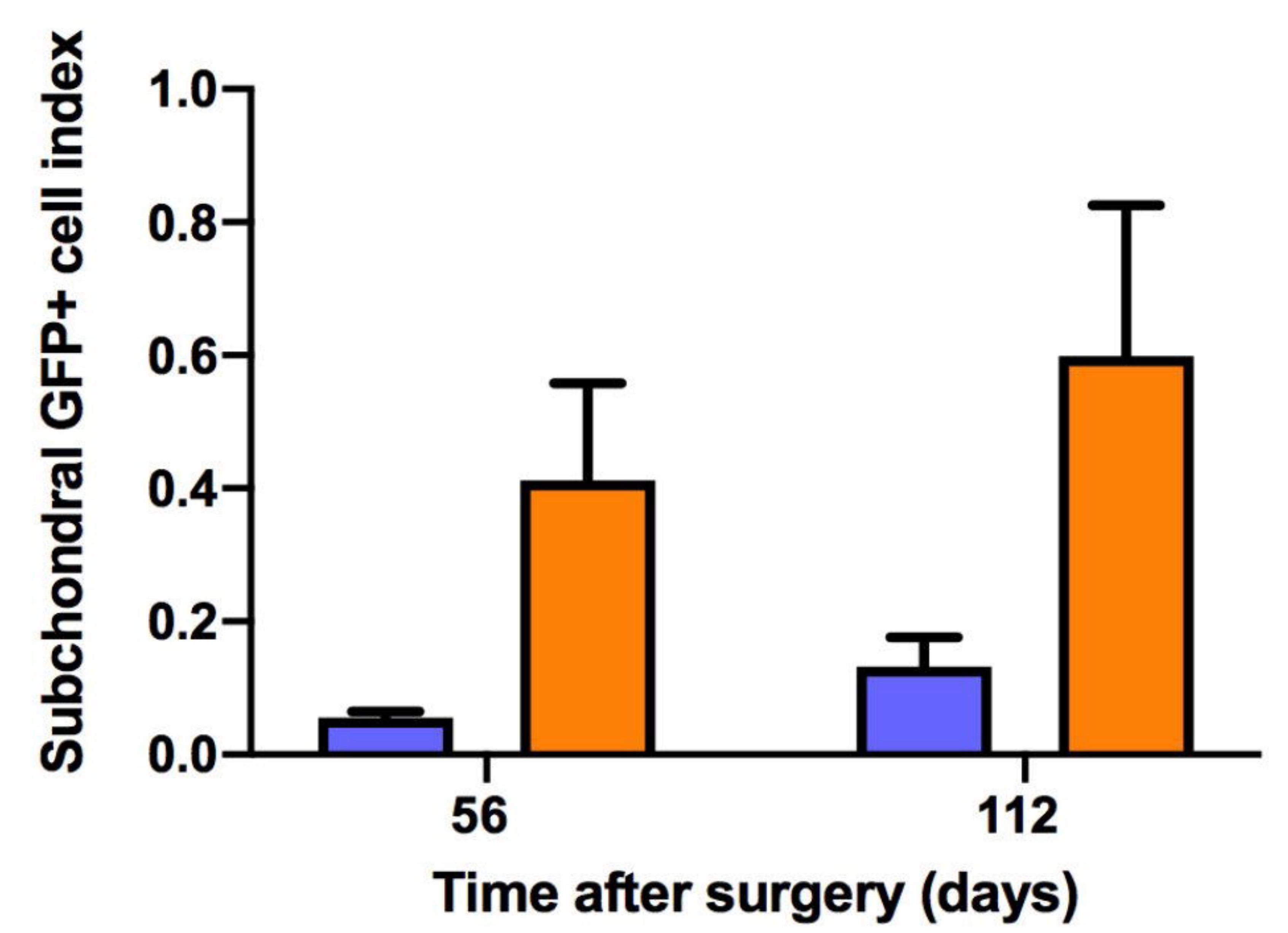

Perichondrium $\square$ Periosteum
D

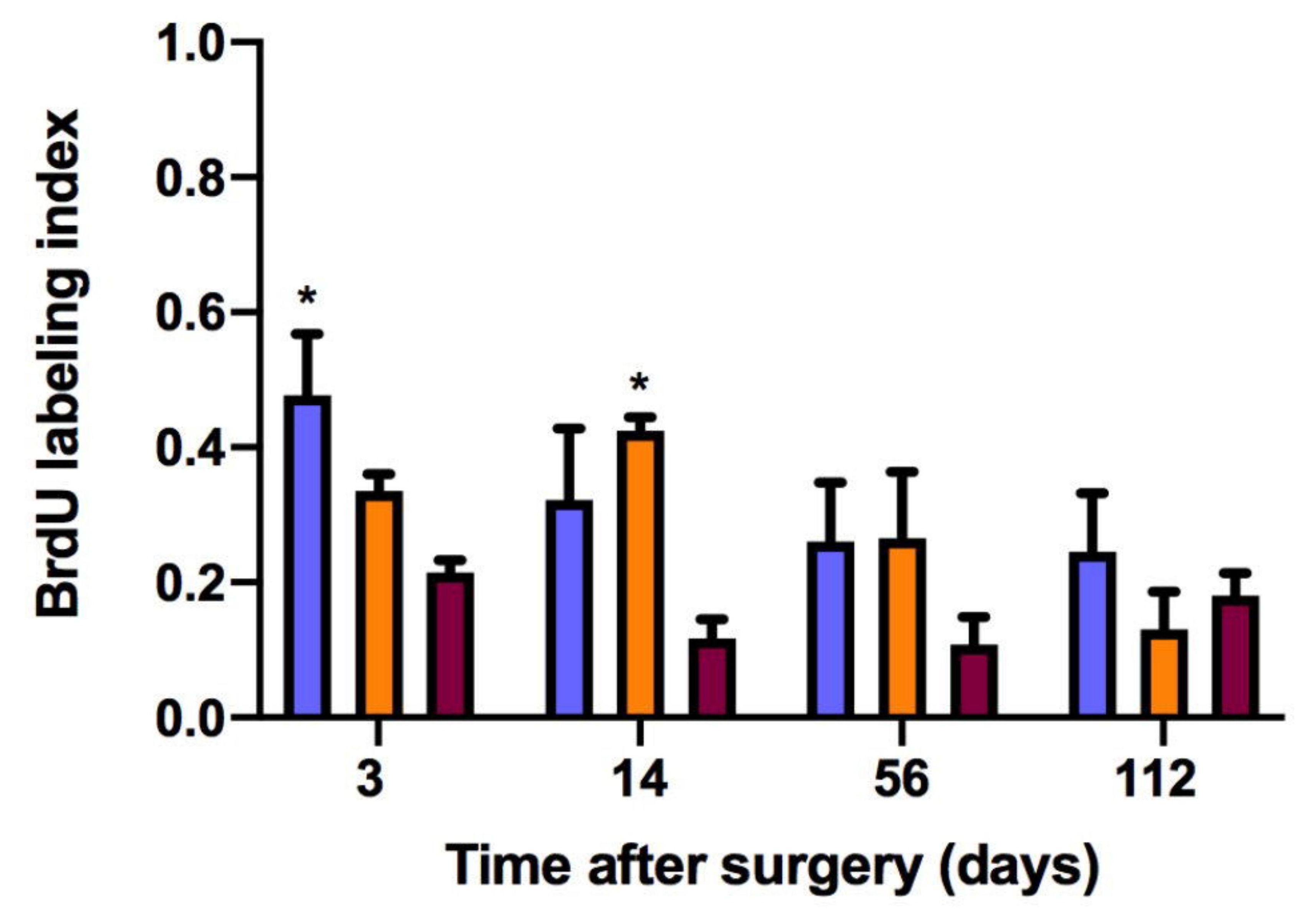

1 Perichondrium $\square$ Periosteum $\square$ Repair Tissue 
A

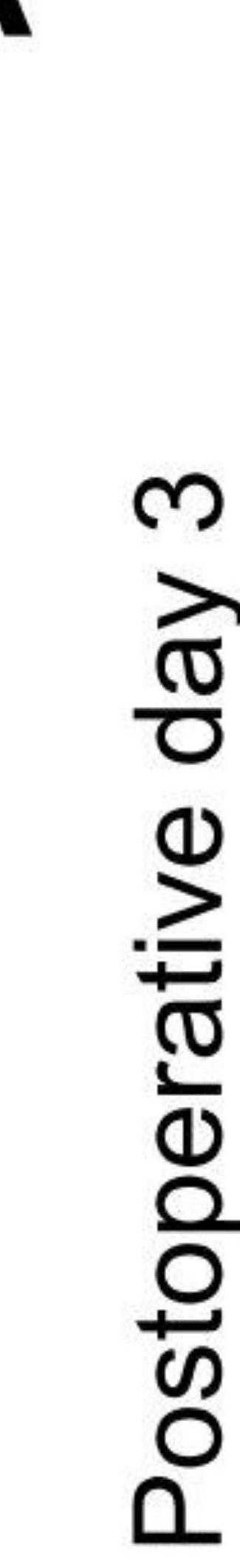

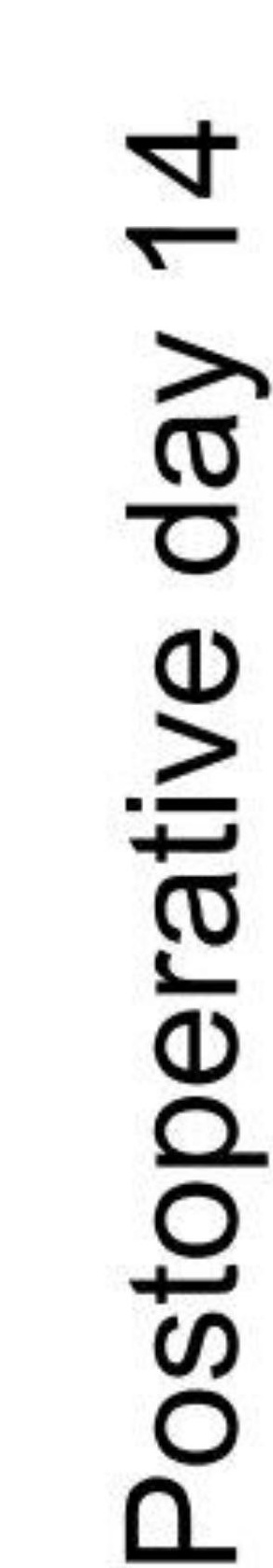

0
10
0
0
0
0
0
0
0
0
0
0
0
0
0

$\stackrel{\Upsilon}{\check{\Sigma}}$

항

$\sum_{0}^{0}$
$\frac{\pi}{0}$
$\frac{0}{0}$
$\frac{0}{6}$
0

○

E

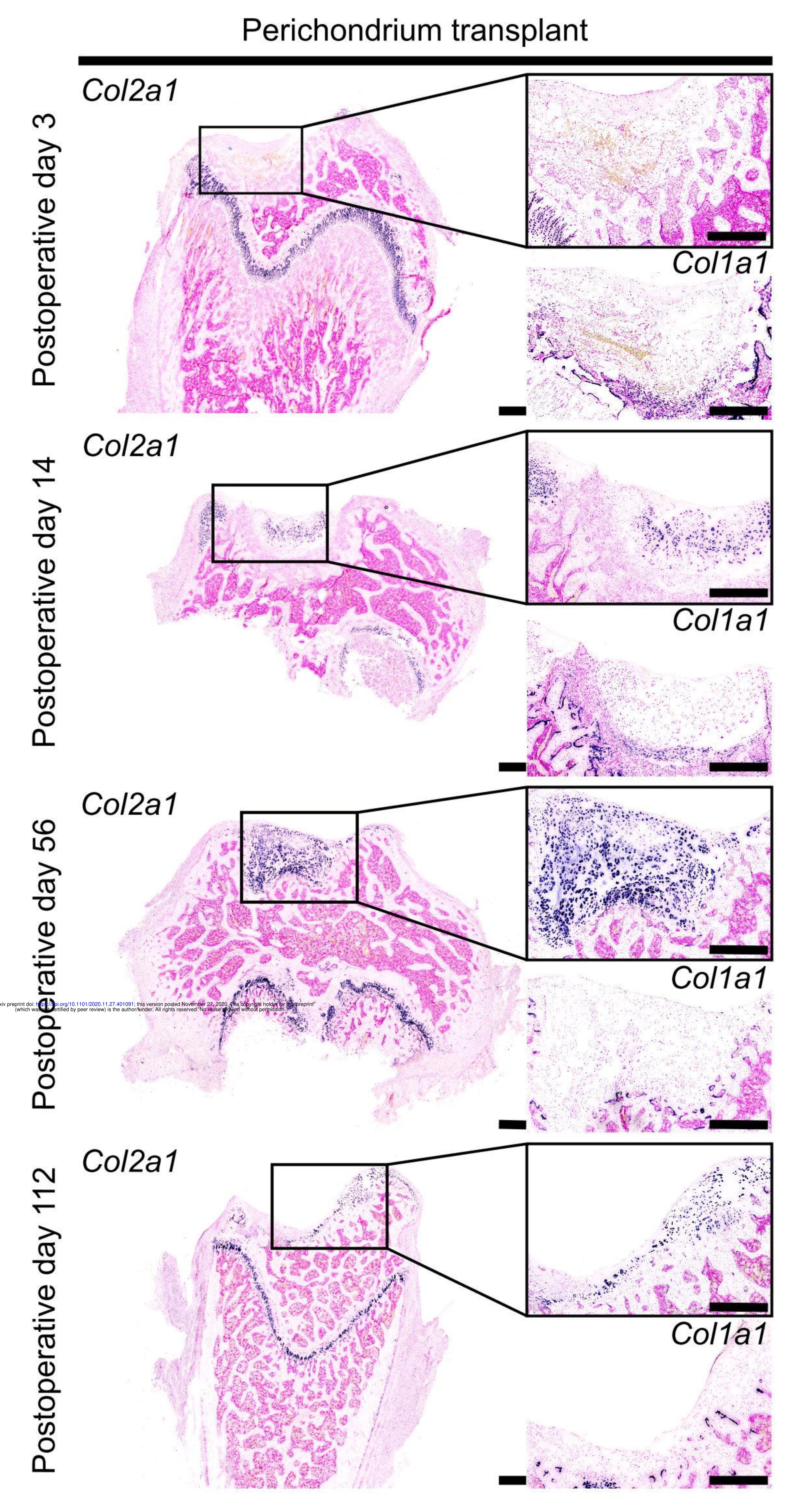

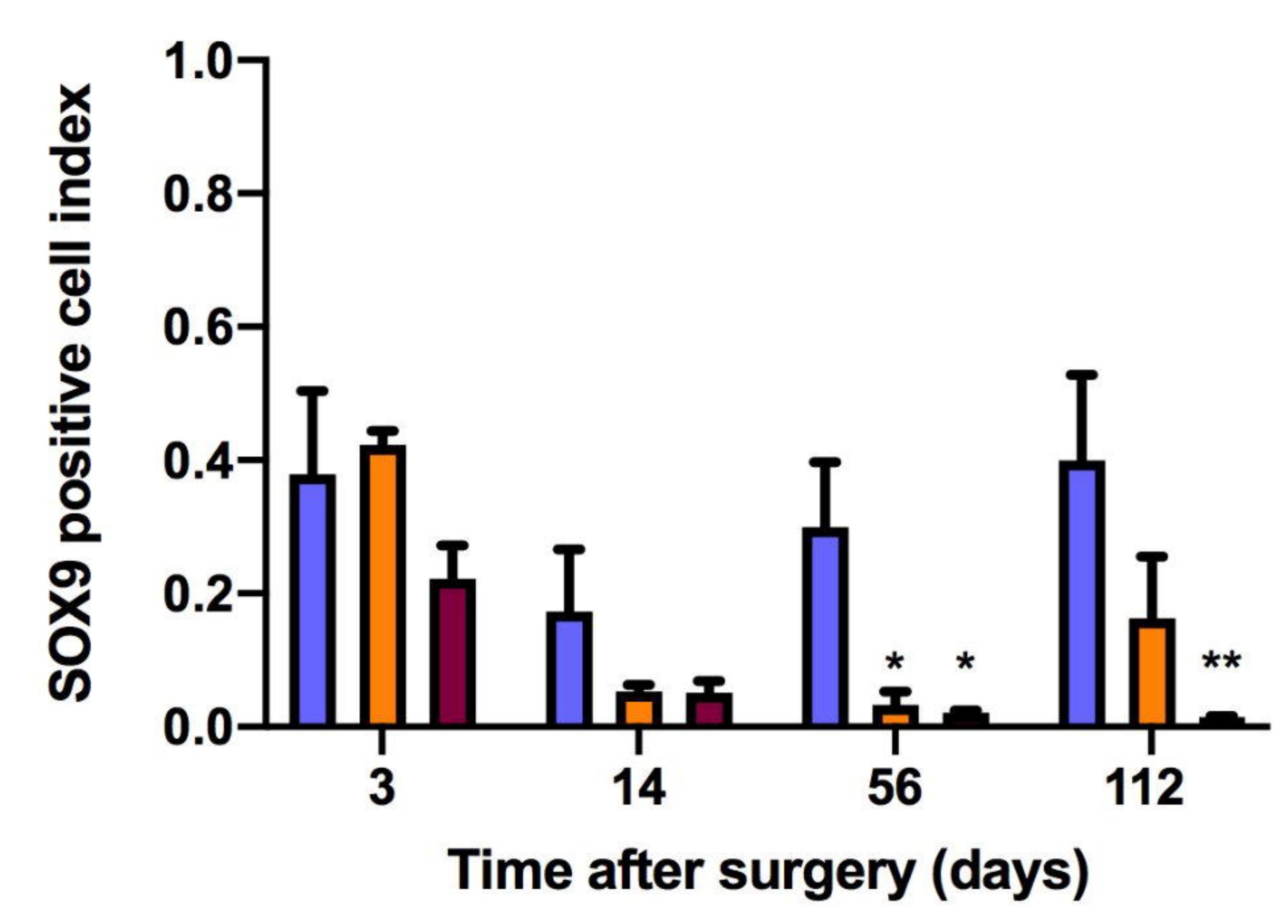

$\square$ Perichondrium $\square$ Periosteum $\square$ Repair Tissue

C

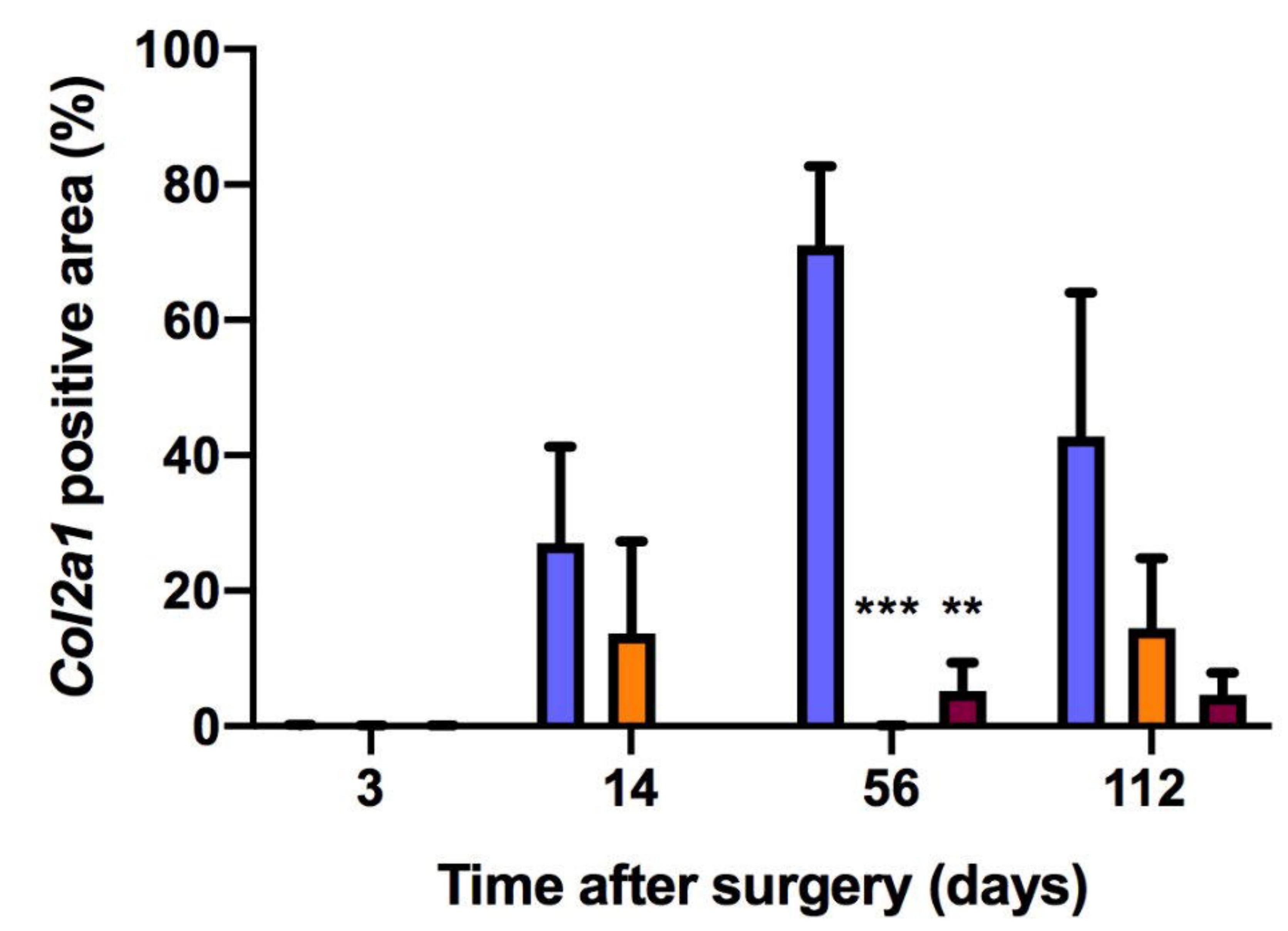

$\square$ Perichondrium $\square$ Periosteum $\square$ Repair Tissue

D

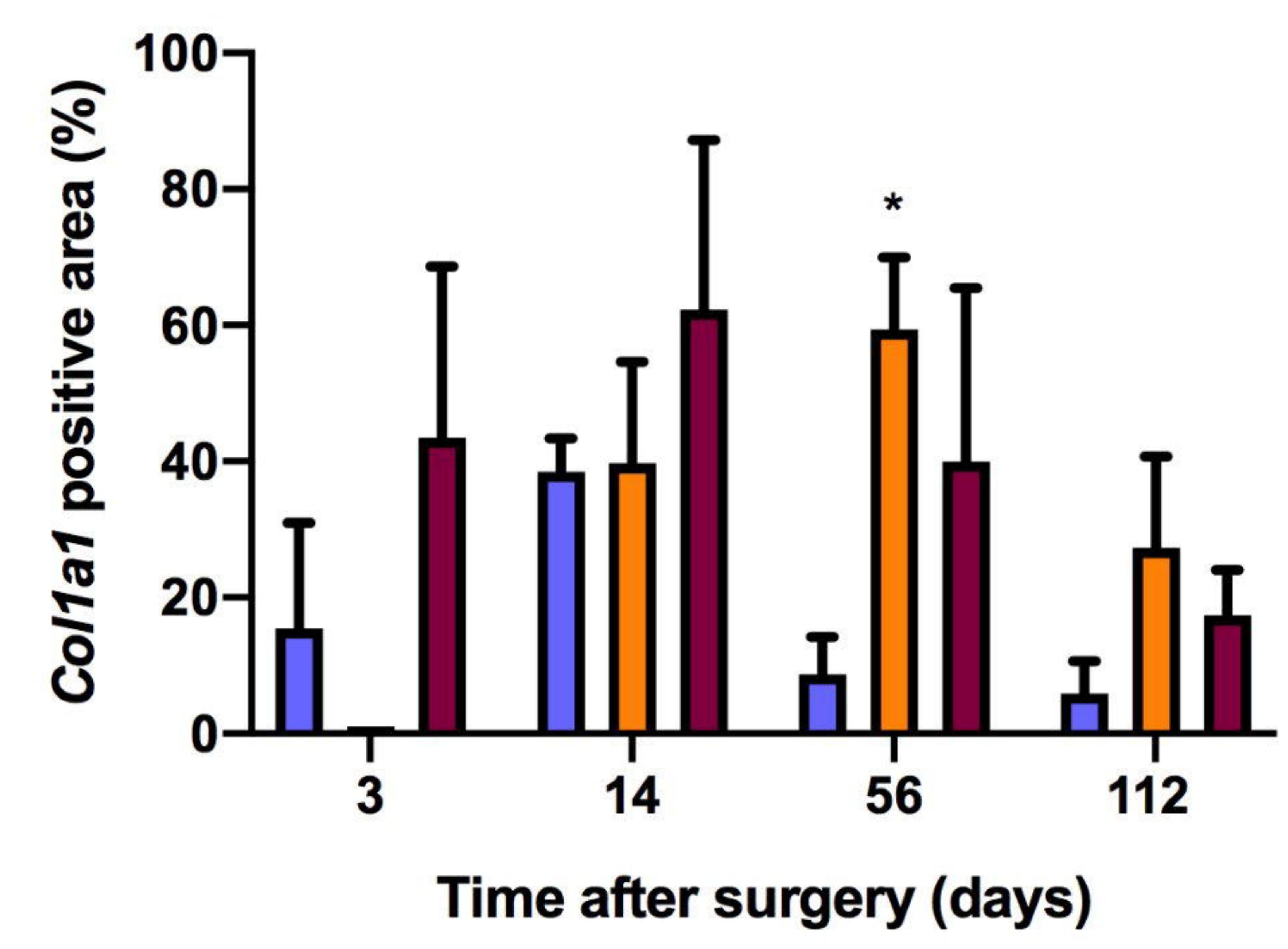

$\square$ Perichondrium $\square$ Periosteum $\square$ Repair Tissue
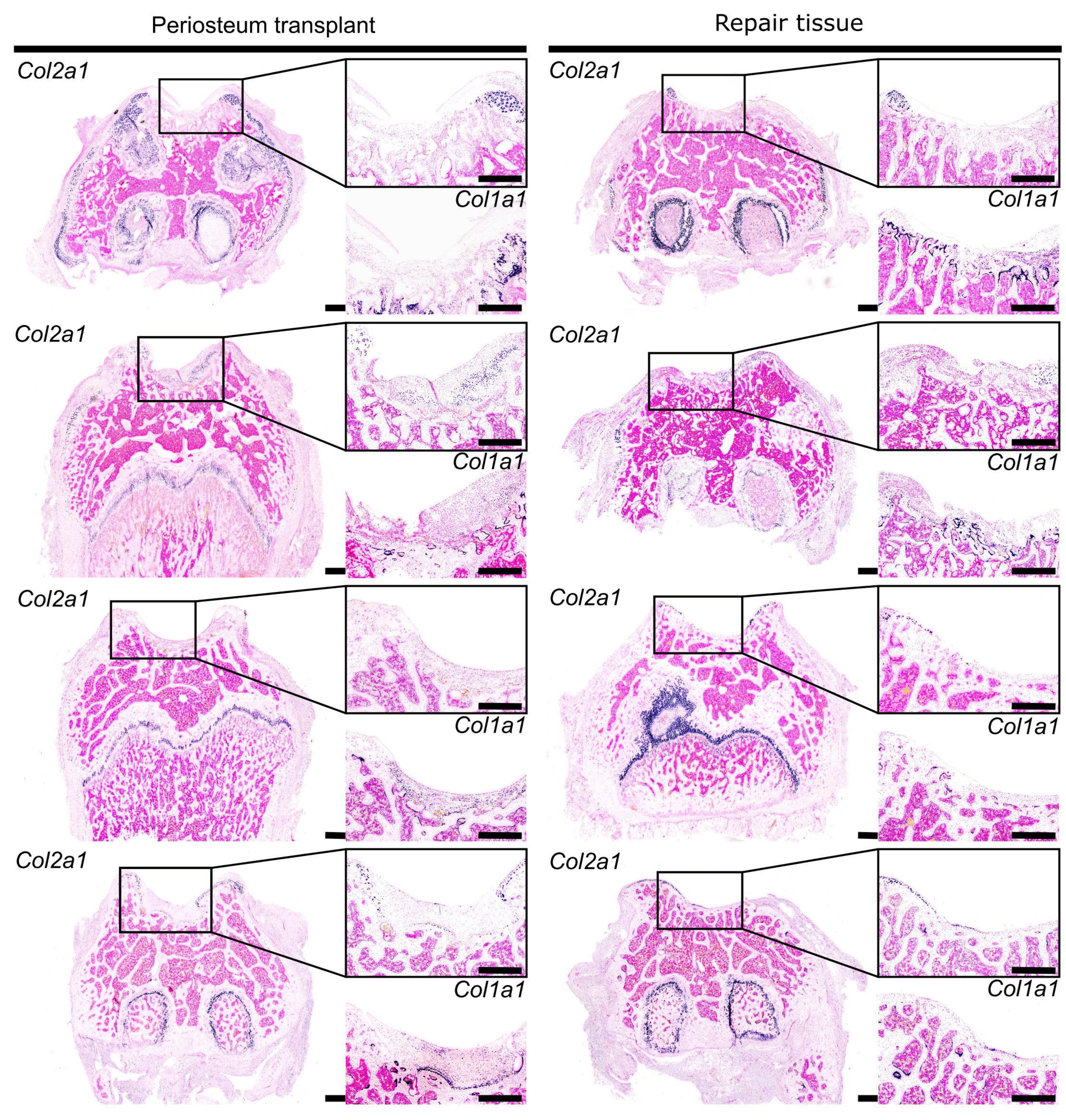
